This PDF is a selection from a published volume from the National Bureau of Economic Research

Volume Title: Tax Policy and the Economy, Volume 16

Volume Author/Editor: James M. Poterba, editor

Volume Publisher: MIT Press

Volume ISBN: 0-262-16210-5

Volume URL: http://www.nber.org/books/pote02-1

Conference Date: October 30, 2001

Publication Date: January 2002

Title: The Fiscal Effects of Population Aging in the U.S.: Assessing the Uncertainties

Author: Ronald Lee, Ryan Edwards

URL: http://www.nber.org/chapters/c10865 


\section{THE FISCAL EFFECTS OF POPULATION AGING IN THE U.S.: ASSESSING THE UNCERTAINTIES}

\section{Ronald Lee and Ryan Edwards}

University of California

\section{EXECUTIVE SUMMARY}

Population aging, accelerating as the Baby Boom generations age, will have important fiscal consequences because expenditures on social security, Medicare, and institutional Medicaid make up more than a third of the federal budget. However, the projected fiscal pressures are far in the future, and long-term projections are very unreliable. Our analysis here has two goals: to examine the fiscal impact of population aging, and to do this in a probabilistic setting. We find that the old age dependency ratio is virtually certain to rise by more than $50 \%$ through the 2030 s, and will probably continue to increase after 2050 , possibly by a great deal. Under current program structures, population aging would be virtually certain to increase the costliness of Federal programs as a share of GDP by 35 percent ( \pm 2 percent) by the 2030 s, and by 60 percent ( \pm 15 percent) in the second half of the century. We project Federal expenditures (excluding interest payments and pre-funded programs) to rise from 16 percent of GDP in 2000 to 30 percent in 2075, almost doubling, while state and local Miller for his help with various parts of the analysis, and James Poterba for helpful comments. 
expenditures rise only modestly relative to GDP. Almost all of this increase is for programs going primarily to the elderly, which rise from 8 percent of GDP in 1999 to 21 percent of GDP in 2075, due mainly to costs of health care for the elderly, with pensions a distant second. We expect that governments will respond to these aging-induced cost changes by altering program structures, so that these conditional projections will not be realized. Looking at social security, we find that raising the payroll tax rate by 1.89 percent would have relatively little effect on the probabilities of early exhaustion, raising the 2.5 percent bound for the exhaustion date from 2024 to 2036, but raising the median date of exhaustion from 2036 to 2070 , and with a 55 percent chance of insolvency within the 75 year horizon. Looking at Medicare, which now costs 2.2 percent of GDP, we project a median share in 2075 of 11 percent, five times as great, with a 95 percent probability interval at 5 percent to 26 percent of GDP. Thus there is a 97.5 percent chance that the ratio will at least double, and a 2.5 percent chance that it will increase at least twelve-fold. Although the future is highly uncertain in many respects, unforeseen demographic or economic change will almost certainly not avert the long-run fiscal crunch. Changing demographic realities will require some combination of substantial tax increases or substantial benefit cuts, or other forms of restructuring.

\section{INTRODUCTION}

Expenditures on social security, Medicare, and Medicaid for nursinghome care together make up more than a third of the federal budget. ${ }^{1}$ These are all programs for the elderly, paid for largely out of taxes on the working-age population. Around 2010, the Baby Boom generations will begin to turn 65 and to draw on these programs, and by 2040, the ratio of elderly people to those in the current working ages will have doubled from about 0.2 to about 0.4 . Clearly, population aging will exert heavy pressure on the federal budget in the coming decades. Nonetheless, there are many questions about this process. The projected fiscal pressures are far in the future, and long-term projections are very unreliable; might not the whole problem evaporate if we just wait? For example, will increased costs in programs for the elderly be offset by decreased expenditures for children elsewhere in the federal budget and in the state and local budgets? Will the passing of the Baby Boom generations bring fiscal relief? Will high-fertility immigrants raise national fertility, as Census projects? Or will fertility in the U.S. move towards low European levels,

1 Institutional Medicaid is the part of the Medicaid program that pays for nursing-home care, primarily for the indigent elderly. 
closer to one child per woman, greatly intensifying population aging? In addition to these demographic sources of uncertainty, there are very substantial economic uncertainties. These are well illustrated by the rapidity with which projections of fiscal doom in the mid-1990s were replaced in the late 1990s by projections of burgeoning surpluses, which have recently been corrected to show declining surpluses over the short run. To formulate fiscally responsible policies, policymakers must have not only best-guess forecasts of the future, but also a measure of the uncertainty surrounding these forecasts.

Before proceeding, some background will be helpful. First, it is important to put population trends in the U.S. into international perspective. Among the industrial nations, the U.S. has high fertility and a stingy public pension system. Combined with middling mortality and immigration, this adds up to relatively mild population aging and to relatively modest fiscal pressure, compared to most European nations or Japan. An OECD study (Roseveare, Leibfritz, Fore, and Wurzel, 1996) found that the fiscal imbalance in the U.S. public pension system over the next 75 years was among the smallest of any of the OECD countries, relative to GDP. The fiscal consequences of population aging for the U.S. will indeed be severe, but in many other industrial nations they will be simply staggering.

Second, it is important to distinguish between the fundamental resource problem posed by population aging, which would exist whatever our institutional structures, and the particular problems that arise specifically because of our institutional arrangements for supporting the elderly, including government programs.

Population aging raises the number of elderly people relative to the number of working-age people, when we hold the age boundary constant at some level such as age 65 . In this sense, population aging occurs partly because individuals live longer, and partly because birth rates are lower, so that younger generations are smaller at birth than the older generations. Longer life, by contrast, results at least in part from better health, so that elderly people at any specific age are more vigorous and less likely to be disabled. For many years, it was feared that people whose lives were saved by declining mortality might be functionally impaired by their close brush with death or by weaker constitutions, so that disability rates at older ages would rise. In the U.S., at least, this has not happened, and indeed rates of disability at older ages are declining at roughly the same rate as mortality itself. Older people will increasingly be functionally able to prolong their working lives (Manton, Corder, and Stallard, 1997; Freedman and Martin, 1999; Crimmins, Saito, and Ingegneri, 1997). People may choose to take their additional 
years of life as leisure years rather than as working years, and consequently they may need to save more or pay higher taxes to support those additional years of leisure. That is a matter of choice, and not caused by aging itself. In this sense, longer life does not cause a fundamental resource problem. By contrast, lower fertility means there are fewer working-age people in the population relative to the elderly, without altering the health or functional status of the elderly. Population aging due to low fertility, unlike that due to low mortality, does fundamentally alter the resource constraints facing society.

Population aging occurs in the context of a particular set of institutions and traditions. In the U.S., the median age at retirement, far from rising with increasing longevity, has declined by five years since 1950 . To some degree, this decline reflects a choice for more leisure at the end of life, influenced by higher lifetime incomes and the public and private pensions which have made it easier for people to realize what would anyway have been their preferred life-cycle plans. That is the positive side of the story. On the negative side, however, both public and private pension programs have incorporated incentives for earlier retirement, whether by design or by accident. In Europe, the easy availability of governmentprovided disability and unemployment benefits for older people has added to these incentives, and extended them to younger ages (Gruber and Wise, 1999). These pension, disability, and unemployment programs create an implicit tax on continuation of work, inducing many people to retire early. When population aging occurs in the context of rigid and distortionary institutions, particularly severe problems may arise. This is the case for most public pension programs throughout the OECD countries, and to a lesser extent for the U.S.

Institutional arrangements surrounding the provision of health care, particularly for the elderly, shape the impact of population aging on public health care costs. Once again, we must distinguish between longer life and lower fertility as causes of population aging. Longer life goes with improved health in old age, and the net effect on health costs appears to be slight (Lubitz and Prihoba, 1984; Lubitz, Beebe, and Baker, 1995). Nor have the costs of typical medical procedures risen in real terms; on the contrary, they may have fallen (Cutler, McClellan, Newhouse, and Remler, 1998; Cutler and Sheiner, 2000). Why, then, are government health care expenditures projected to rise so strongly relative to GDP over the twenty-first century? First, because lower fertility will mean fewer workers to bear the cost of health care for the elderly (that is, future GDP will be lower than otherwise). Second, because populations of industrial nations have a great appetite for the costly new procedures made available by striking technological advances in medi- 
cine over recent decades, advances which are expected to continue in the future. In the U.S., these two factors-population aging due to low fertility and the purchase of costly new biomedical technologies-are expected to account for roughly equal shares of the projected increased expenditure on health care relative to GDP (Lee and Miller, 2001b). The portion of the increase due to low fertility and population aging cannot be avoided, except possibly by pro-natalist and pro-immigration policies. It is important to make sure that the other part, due to increased quantity and quality of health care services consumed, is growing in a way consistent with individual and social preferences, not simply because of distortions arising from the structures of institutions formed decades ago.

It is easy to exaggerate the fiscal pressures generated by population aging. In practice, the structure and generosity of programs do not remain fixed as population changes, and changing population age distributions have only modest power to explain government expenditures on social welfare programs in the past. The structure and generosity of programs may be rigid in the short term, but in the longer term these too adjust. We should keep in mind, however, that even if the fiscal pressures are mitigated by program changes, these mitigating changes may simply pass costs on to the beneficiaries, in the form of later retirement or reduced medical benefits.

This paper will begin by discussing demographic change in the U.S. Next, it will discuss approaches to assessing the uncertainty of projections, which is then followed by an overview of our own probabilistic projections of population aging. Then it will consider how population aging alters the budgetary trade-offs that constrain government programs in the aggregate, contingent on the continuation of current program structure. An overview of stochastic budget projection techniques follows, motivated by a summary of deterministic predictions. The paper will then discuss in more detail the uncertainty of projections for social security and for Medicare. In the final section, we discuss our results.

\section{POPULATION CHANGE IN THE U.S.}

\subsection{Fertility}

Over the past two centuries in the U.S., the economic roles of women and children have changed, incomes have risen dramatically, mortality has declined, the frontier has been settled, and contraceptive technology has advanced. Consequently, fertility has declined steadily from 7 or 8 births per woman in 1800 to 2.0 births per woman today, a decline 
interrupted by the Baby Boom between 1946 and 1965. Similar factors have led to a fertility decline in other industrial countries as well. However, fertility in the U.S. has always been high compared to levels in other industrial populations. The average level for European populations is 1.4 births per woman, with some countries like Spain, Italy, and Germany close to 1.2, and a few smaller populations close to 1.0. Will fertility in the U.S. decline toward European levels in the coming decades? Two considerations reduce the likelihood. First, European women typically report on surveys that they would like to have 2 children on average, suggesting that fertility may rise in the future. Second, the average age of childbearing has been rising steadily in most European countries in recent decades, as women postpone giving birth. This trend distorts the standard fertility measure downward by 0.2 to 0.4 births, relative to fertility levels over the life cycle of these women, again suggesting that European fertility may rise in the future.

Fertility is high in the U.S. in part due to the higher fertility of minority groups such as African Americans, Latinos, and Asians. Projections indicate that the population share of non-Hispanic Whites will decline from around 70 percent today to around 50 percent by 2050 . Will growing population shares of these minority groups lead to higher aggregate fertility? The U.S. Census Bureau has assumed in its recent projections that it will. We are skeptical. It is mainly first-generation immigrants who have high fertility; by the third generation fertility has historically converged to the levels of the general population (Smith and Edmonston, 1997). For example, first-generation Latino women have more than three births on average, whereas third-generation Latino women have only two. Furthermore, fertility in the sending countries in Latin America and East Asia is rapidly falling. In Mexico, fertility is now down to 2.6 births per woman and falling rapidly, while many populations in East Asia, including China, have fertility below replacement level. This suggests that future immigrants will not have fertility that is much higher than the rest of the U.S. population.

Overall, therefore, we believe it is reasonable to project, as a point estimate, that fertility levels continue at the current level of about 2.0, while noting that there is a great deal of uncertainty about this central forecast.

\subsection{Mortality}

Improvements in nutrition, public sanitation and hygiene, personal habits, biomedical technology, and health service delivery have caused mortality declines throughout the world. Dramatic progress first against infectious disease, and then against chronic and degenerative disease, 
has brought life expectancy in most industrial nations from 30 to 40 years at birth in the early nineteenth century to 75 to 80 years at birth today. The acceleration of the rate of decline in death rates at the older ages, even above 100, in recent decades has been particularly striking (Kannisto, Lauritsen, Thatcher, and Vaupel, 1994). Mortality is expected to continue to decline in the twenty-first century, but how far and how fast is open to question and controversy. The pessimists believe that it will be difficult to raise life expectancy above 85 years without truly revolutionary medical advances to slow the progress of aging itself (Fries, 1980, 1984; Olshansky, Carnes, and Desesquelles, 2001; Board of Trustees, 2001). Optimists believe that advances in stem-cell and genetic therapies may raise life expectancy as high as 150 years in this century. Forecasting methods based on long-run trend extrapolation suggest that life expectancy in the U.S. will rise from its current 76.7 years to around 86 years by 2075, plus or minus 4 years (Lee and Carter, 1992; Lee and Miller, 2001a; Tuljapurkar, Li, and Boe, 2000). Our forecasts in this paper will be based on this latter approach.

\subsection{Immigration}

The annual number of net immigrants to the U.S. has risen linearly since 1950, and shows no signs of decelerating in recent years. Nonetheless, because immigration is a policy variable, we have elected to follow the Social Security Actuaries in assuming that the net annual number will remain at 900,000 . Certainly a case could be made for forecasting the linear trend to continue.

\subsection{Projections by the U.S. Bureau of the Census and the Social Security Administration}

While the assumptions about net immigration are very similar between Census and SSA, the assumptions for fertility and mortality are quite different. The SSA assumes that fertility will decline from about 2.05 children per woman today to 1.95 by 2025 , remaining constant thereafter. The USBC assumes that fertility will instead increase from its current level to 2.22 in 2050 , then declining slightly to 2.20 in 2075 . The difference of about 0.25 in fertility implies an eventual difference of about 0.5 percent per year in the population growth rate, which is substantial. Furthermore, the SSA assumes a slower increase in life expectancy, to 81.7 in 2050 and 83.0 in 2075, vs. 84.0 and 87.1 for the USBC. Thus by 2075 , Census has life expectancy higher by four years than the Actuaries. These differences in fertility and assumed mortality decline lead Census to predict more rapid population growth, and indeed, while the SSA projects growth at 0.3 percent per year in 2050 and 2075, Census projects 0.7 
percent per year in both years, more than twice as rapid. By 2075, the population projected by Census is 80 million greater than that by the SSA. Higher fertility eventually makes a population younger, while higher life expectancy makes it older, so the differences in the projected old age dependency ratio (OADR) are not as great as otherwise. In 2050, the SSA OADR is lower, and in 2075, the Census OADR is lower.

\subsection{Population Projections}

Based on this discussion of fertility, mortality, and immigration, it is straightforward to carry out the arithmetic of a population projection, generating forecasts for total population size and age distributions from which measures such as the OADR could be calculated. Before doing this, however, we will pause to consider how much confidence should be put in results of this sort.

\section{THE UNCERTAINTY OF PROJECTIONS}

The public and the government have become well aware of the impending fiscal pressures that will be caused by population aging as the Baby Boom grows older. Major changes in social security and Medicare, the programs expected to be most heavily affected, are currently under consideration. Indeed, important changes in social security were already made in the early 1980s, with the expectation that they would help restore long-run balance to the system far into the future. Those expectations now appear to have been too optimistic, for a variety of reasons.

Might our current expectations about population aging and its consequences again turn out to be incorrect? Certainly they will. The projection horizon for social security is 75 years, but projection only a few years into the future is fraught with error. The question is not whether there will be errors, but rather how large and how important the errors will be. For this reason, it is very important that forecasts present not only the best guess about future outcomes, but also an indication of the uncertainty surrounding them.

The typical projection results from assumptions about trajectories for several input variables, such as fertility, mortality, immigration, productivity growth, inflation, interest rates, and so on. The traditional way of assessing and conveying the uncertainty of a long-run projection begins by developing high, medium, and low trajectories for each of the input variables. It then bundles combinations of these trajectories together to calculate high, medium, and low projection scenarios. The way the bundling is done depends on the purpose of the projection, and has an important influence on the results. Consider, for example, population 
forecasts. The Social Security Actuaries bundle together high fertility, high mortality, and high immigration, because all of these conduce to a lower OADR and to lower projected costs per worker. Census bundles together high fertility, low mortality, and high immigration, because all of these conduce to more rapid population growth. The resulting highlow bounds for projected outcomes will differ. For example, the Social Security projections of population size in 2075 range from 344 million to 486 million, whereas those from Census range from 304 to 809 million. At the same time, the Social Security projections for the OADR in 2075 range from 0.314 to 0.563 , whereas those from Census range from 0.343 to 0.494 . For population size, the high-low range of Census is 3.5 times as great as that of the Social Security projections. For the OADR, the high-low range for Social Security is 1.6 times as great as that of Census. Since they give very different indications of the uncertainty associated with their forecasts of different items, they cannot both be right.

There are four ways in which the scenario-based approach to assessing uncertainty of forecasts is seriously flawed. ${ }^{2}$ First, by its very nature, it is forced to make patently false assumptions about the correlation structure of forecast errors in the input variables-specifically, that all the cross-correlations in errors are either +1.0 or $-1.0 .^{3}$ This problem results from the bundling just described. When Social Security bundles high fertility with high mortality, it assumes that a large positive forecast error for fertility always goes with a large positive forecast error for mortality. Census assumes the opposite. The second problem is similar, but applies across time rather than across variables. The scenario method must assume that the input variables will either always follow the highest plausible trajectory or always follow the lowest one, thereby ruling out the possibility of long-run fluctuations like the Baby Boom, which could produce greater variations in some outputs such as the OADR. Here, it is assumed that the correlation of errors across time is always +1.0 . Third, the indications of uncertainty attached by the scenario method to differing outcome variables such as population size,

${ }^{2}$ Although flawed for assessing uncertainty, scenario-based projections can be very useful for analytic purposes and for sensitivity tests.

${ }^{3}$ In principle, one could calculate the error from each of the past Census or SSA forecasts of fertility and mortality, by comparing the forecasts with subsequent realized outcomes, and then these errors could be used to find the actual ex post correlation of errors in government agency forecasts of fertility and mortality. Unfortunately, this has not yet been done. Alternatively, we could fit time-series models to fertility and mortality, and examine the correlation of the residuals. This results in correlations that are insignificantly different than 0 . However, the time-series models fit short-term movements in the series, whereas forecast errors arise most dramatically from errors in forecasting long-term levels and trends. 
births, fertility, life expectancy, and OADRs are inconsistent. This happens because each of these outcomes will reflect differing ways of averaging out the errors in forecasting inputs, with differing degrees of cancellation of errors, but the method is unable to take this into account, due to the assumed rigid covariance structure for errors. Fourth, the scenario method is intrinsically unable to assign probabilities to its high-low ranges. (See Lee, 1999, and Lee and Tuljapurkar, 2000, for an extensive discussion of the problems with scenario-based forecasting.)

The kinds of inconsistencies that result from scenario-based forecasts are illustrated in Table 1, which contrasts uncertainty ranges for different items in forecasts by Census and Social Security, and probabilistic forecasts by Lee and Tuljapurkar, to be discussed in a moment. We see that the range for children in 2050 is larger for Census than for Social Security; for workers, the Census range is twice as wide; for the elderly, it is three times as wide; but for the OADR it is only one-seventh as wide, while for the total dependency ratio it is very much wider. For Census, the working-age population is supposedly known within plus or minus 26 percent, and the elderly population within plus or minus 27 percent, yet their ratio, the OADR, is supposedly known within 3 percent! Clearly these indications of uncertainty are inconsistent. Similarly, for Social Security, the total dependency ratio supposedly has only tiny uncertainty, which is again inconsistent. The probabilistic forecasts

TABLE 1

High-Low Ranges for Forecasts of Selected Items to 2050, as Percentage of Middle Forecast

\begin{tabular}{lccc}
\hline & \multicolumn{3}{c}{ Range (\%) } \\
\cline { 2 - 4 } Item & Census (1992) & $\begin{array}{c}\text { Soc. Sec. Actuaries } \\
(1992)\end{array}$ & $\begin{array}{c}\text { Lee and Tuljapurkar } \\
(1994)\end{array}$ \\
\hline Children & \pm 44 & \pm 31 & \pm 49 \\
Working age & \pm 26 & \pm 13 & n.a. \\
Elderly & \pm 27 & \pm 9 & \pm 10 \\
OADR & \pm 3 & \pm 21 & \pm 35 \\
65+/20-64 & \pm 10 & \pm 0 & \pm 24 \\
Total Dep. Ratio & & & \\
$(<20+65+) / 20-64$ & & & \\
\hline
\end{tabular}

Calculated as (high-low)/(2×middle). For Census, high minus low; for Social Security Actuaries, high cost minus low cost; for Lee and Tuljapurkar, upper 95-percent bound minus lower 95-percent bound. The date of publication of the forecast is indicated; all are for the year 2050, which is the latest published by the Census Bureau. For Census, children are <18; for the others, $<20$. Elderly are always $65+$. Lee and Tuljapurkar (1994) did not publish a probability bound for the working-age population, so none is shown. 
shown in the last column have fully consistent indications of uncertainty, taking into account all covariances.

Although the traditional and widely used scenario method for assessing uncertainty of forecasts is seriously flawed, there are two other general approaches that are more useful. The first is analysis of the performance of past forecasts, and from that analysis, development of probability distributions for current forecasts on the assumption that the methods used and other circumstances are sufficiently similar in the past and future to make this useful. This approach is illustrated by the probability distributions provided for Congressional Budget Office (CBO) forecasts of the federal surplus (CBO, 2001). The CBO had only a short historical record of forecast performance to analyze, so its probability distributions were provided for only five years ahead, a serious limitation. Another difficulty is that a separate historical analysis of forecast errors must be conducted for each variable of interest. For an application of this approach in demography, see National Research Council (2000, chapter 7). For an application to the Social Security Actuaries' forecasting record, see Lee and Tuljapurkar (2000). The second approach is to develop stochastic forecasts that incorporate errors in the forecast of each input, and reflect their propagation through the forecast process.

Here we will follow a variant of this second approach, in which timeseries methods are used to fit stochastic models for each input variable, and the propagation of errors is tracked through stochastic simulation. With this approach, a probability distribution can be calculated for any outcome of interest, including joint probability distributions for multiple outcomes. In most cases, we constrain the central trajectory for each input (that is, the long-run mean) to match an assumption by the Social Security Actuaries, the Centers for Medicare and Medicaid Services (previously the Health Care Financing Administration), or the Congressional Budget Office, but this is not the case for mortality. In all cases, the variances and covariances are estimated from the historical data series.

\section{STOCHASTIC POPULATION FORECASTS}

The population forecasts we report below are distinctive in two respects. First, they reflect the choices for central trends in fertility, mortality, and immigration that we have just discussed, which differ from those in the projections by Social Security (in having lower mortality) and the Census Bureau (in having lower fertility). Second, they are probabilistic forecasts based on a new method (Lee and Tuljapurkar, 1994).

Figure 1 shows the forecast for the OADR (defined as population $65+$ divided by the population 20 to 64 ). Focus first on the central Lee- 
FIGURE 1. Old-Age Dependency-Ratio Forecasts: 1999 to 2080

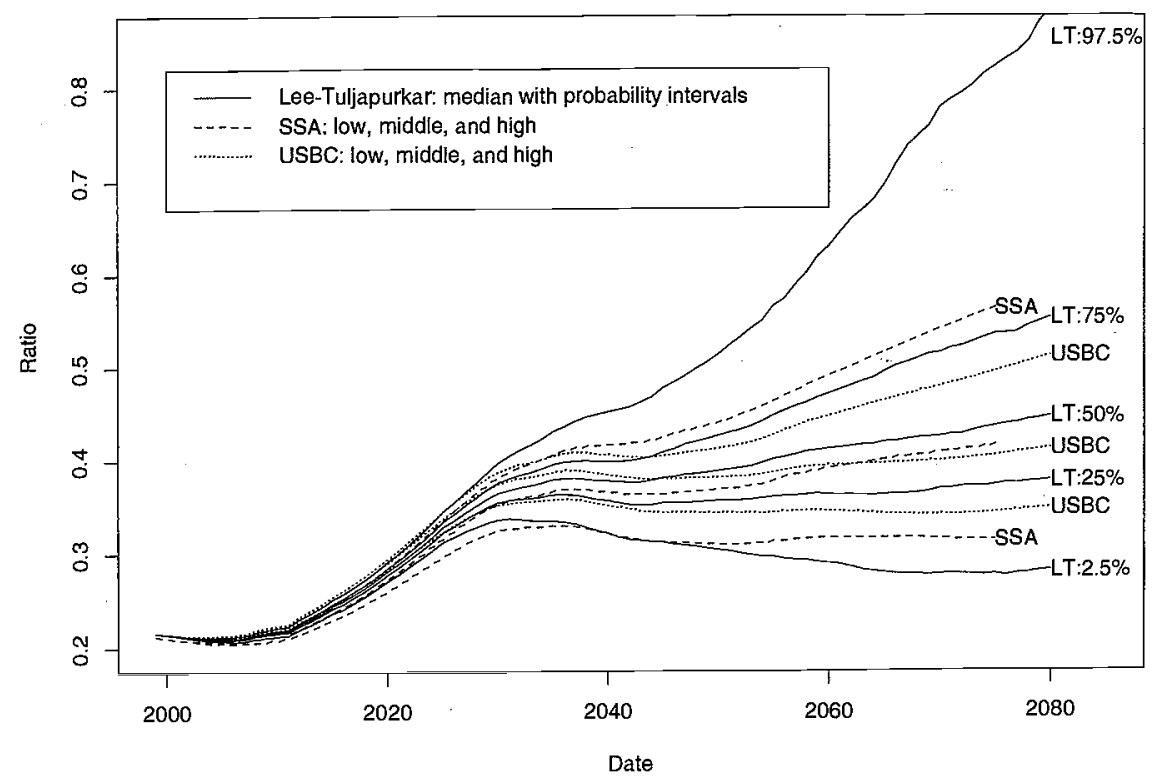

Tuljapurkar forecast, labeled "LT." Over the next decade, there will be a slight decline in the OADR, while the smaller generations born when fertility was low during the 1930s and early 1940s move into old age. The larger Baby Boom generations begin to reach 65 in 2010, and we see rapid aging for the next twenty years, slowing or slightly reversing as the Baby Boomers die off, and the smaller Baby Bust generations born since the mid 1960s enter old age. Then the OADR resumes its upward trend. Note that the Baby Boom generations are not the cause of population aging; they merely usher it in. It is caused by low fertility and falling mortality, and unlike the Baby Boom, these are expected to continue indefinitely.

The figure also plots quantiles of the probability distribution. There should be a 50-percent chance that the true future value falls between the 25- and 75-percent bounds, and a 95-percent chance that it falls between the 2.5- and 97.5-percent bounds. Before 2020, all the uncertainty in the ratio is due to uncertain survival of people through the working ages and of the elderly who are already born. After 2020, the uncertain births due to uncertain fertility in 2000 and thereafter begin to enter the working ages, adding increasing uncertainty to the ratio as time passes. After 2040, uncertain fertility is applied to uncertain numbers of young 
women, compounding the uncertainty in the ratio. Finally, after 2065 the highly uncertain size of birth cohorts begins to affect the projected numbers of elderly in the numerator as well as workers in the denominator. Note also that there is nearly twice as much uncertainty in the upward direction as in the downward direction. ${ }^{4}$ By 2075 , there is a 2.5-percent chance that the increase in the OADR will be twice as large as the central forecast, and a 2.5-percent chance that it will be only one-fourth as large as forecast. In any case, however, it is virtually certain that substantial population aging will occur over the next forty years.

For comparison, Figure 1 also plots the central projections by Social Security (SSA) and Census (USBC), along with their non-probabilistic high and low projection variants. We note that there are not major differences in the central forecasts, but that after 2040, the Census and Social Security projection ranges have much less than 95-percent probability coverage. The upward range for both Census and Social Security is close to the Lee-Tuljapurkar 75-percent bound, meaning that the true value would be expected to exceed the high bound for these projections about 25 percent of the time, if the Lee-Tuljapurkar probability distribution is correct.

\section{HOW POPULATION AGING AFFECTS GOVERNMENT BUDGETS}

It is straightforward and natural to use population projections to project the future costs of benefits, on the assumption that program structures will remain as they are now. Such projections are useful for tracing out the implications of current policies, and thereby informing decisions about changing those policies. These exercises should be viewed only as conditional forecasts, however. Studies of the effect of population aging in the past on government budgets show much smaller effects, because in practice programs are adjusted. For example, Gruber and Wise (2001) examined data for OECD countries over time, and found that a 10percent increase in the proportion of elderly in the population led to a 5percent increase in expenditures on the elderly, so that expenditures per individual old person declined while the aggregate expenditure on the elderly increased (that is, they found an expenditure elasticity of 0.5 , measured relative to GDP). They also found that spending in other areas of the budget was reduced, so that total government expenditures as a share of GDP did not change with population aging.

${ }^{4}$ This is typical of the probability distributions for population forecasts. Population growth is multiplicative, so uncertainty is lognormally distributed. 
FIGURE 2. Benefits by Program and Age

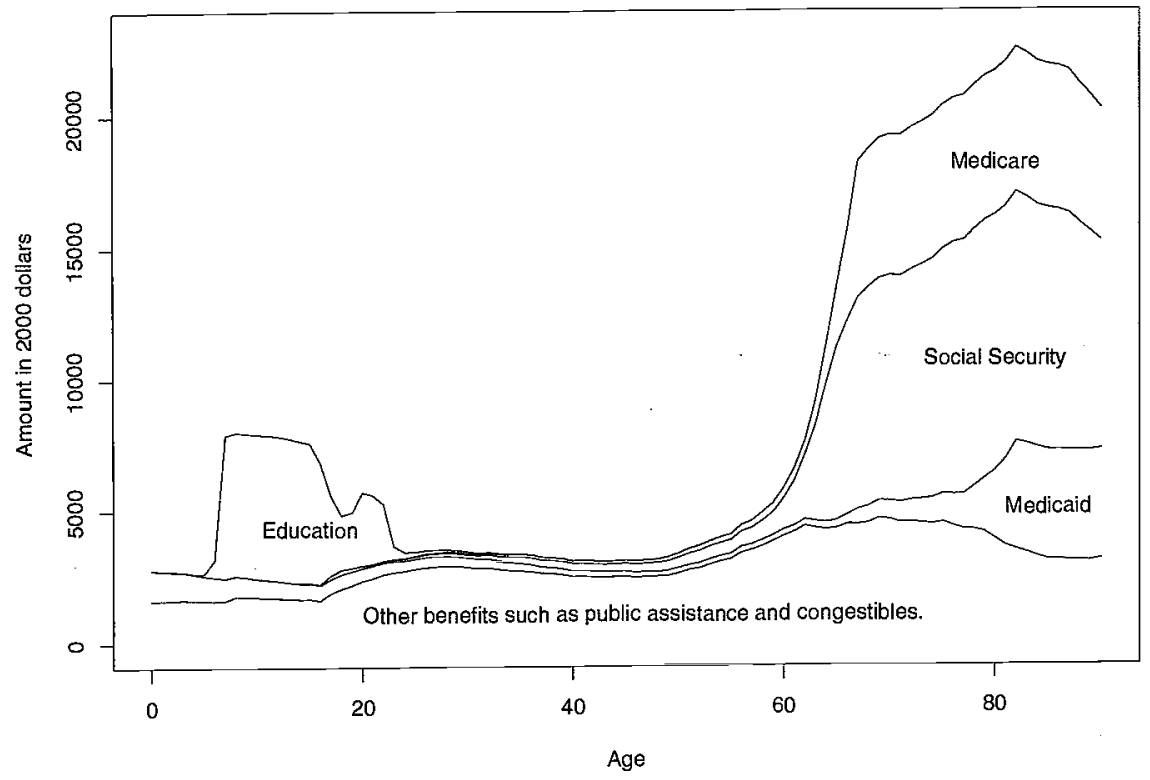

Evidently population change does not dictate outcomes, but rather alters the trade-offs and constraints faced by policymakers. In the rest of this section, we will consider how this works. We begin by presenting the current cost of benefits received by age in the U.S., $\beta(x)$, and tax payments by age, $\tau(x)$. Figure 2 plots $\beta(x)$, broken down by broad category of expenditure, but originally based on 25 individual or household benefit programs (school lunches, TANF, energy assistance, SSI) plus additional non-individual programs (roads, police, etc.) (see the Appendix for explanation of how these were estimated). The data refer to average amounts per surviving individual at each age, so keep in mind that there are relatively few survivors to very old ages. They include all government expenditures at the federal, state, and local levels, except for expenditures on public goods (mostly defense spending). Expenditures which do not accrue to individuals or households are assigned on a per capita basis. The concentration of expenditures on children and on the elderly is apparent. The average elderly person receives over $\$ 20,000$, which is about four times as much as the average child. Note that Medicaid expenditures for elderly people are primarily for nursing-home care.

Figure 3 plots $\tau(x)$, again per surviving individual at each age, and broken down by kind of tax (see the Appendix for details of construc- 
FIGURE 3. Taxes by Program and Age

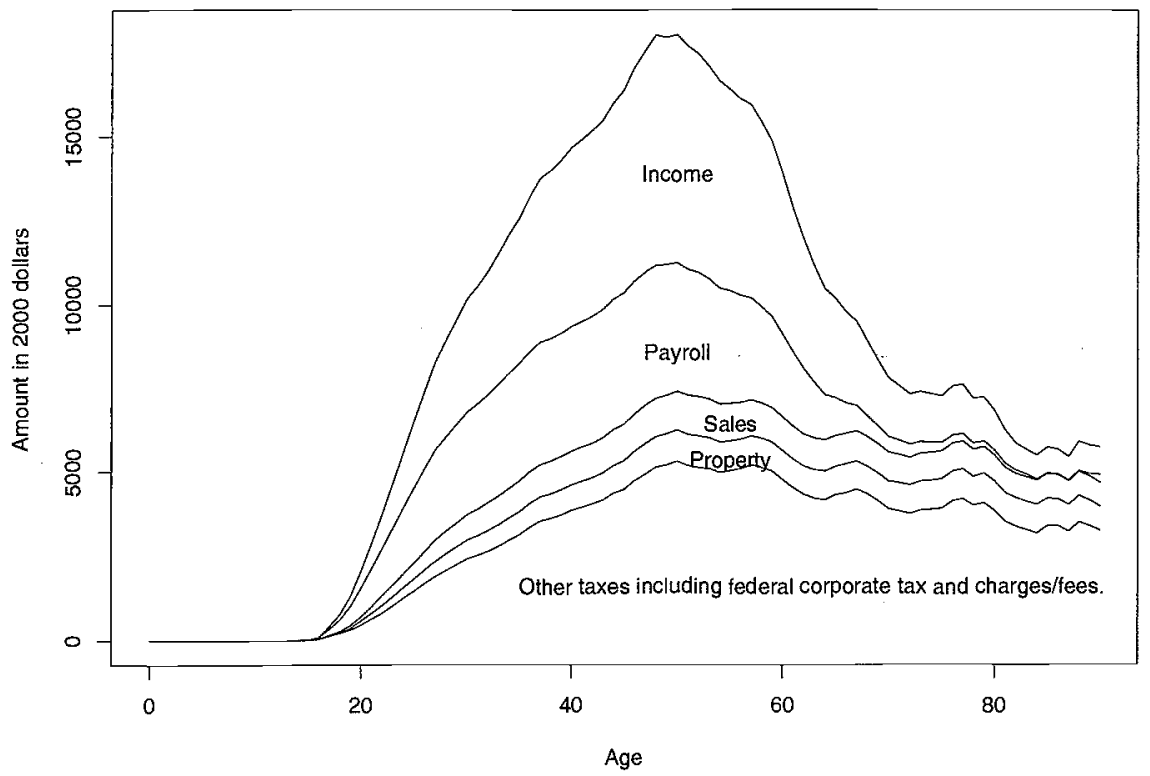

tion). Note that for some kinds of taxes, the elderly pay about the same amount as prime-age adults - notably corporate tax (inferred from dividend income), property tax, and sales tax. However, because they don't have much labor income, they pay far less payroll tax and income tax, and in total pay much lower taxes than prime-age adults.

To see how population aging will affect the costliness of our current age-benefit structure, we can calculate how the changing population age distribution would alter the ratio of total taxes to total benefit expenditures. We will call this ratio the fiscal support ratio. We could imagine an individual or a planner weighing the utility of receiving the benefit schedule $\beta(x)$ over the life cycle, vs. receiving the after-tax income that would be released by reducing or eliminating the programs that $\beta(x)$ comprises. While individual utility from the stream of benefits is distributed over future years of the life cycle, the cost in taxes is determined by the crosssectional balanced-budget constraint in each year, which is in turn determined by the population age distribution. This interplay between the individual life cycle and the cross-sectional population age distribution generates the fiscal effects of population aging. In an important sense, the population age distribution determines the price of the vector of lifecycle benefits, $\beta(x)$. This price is the ratio of aggregate taxes to benefits, 
FIGURE 4. Projected Fiscal Support Ratio by Level of Government, 2000 to 2100

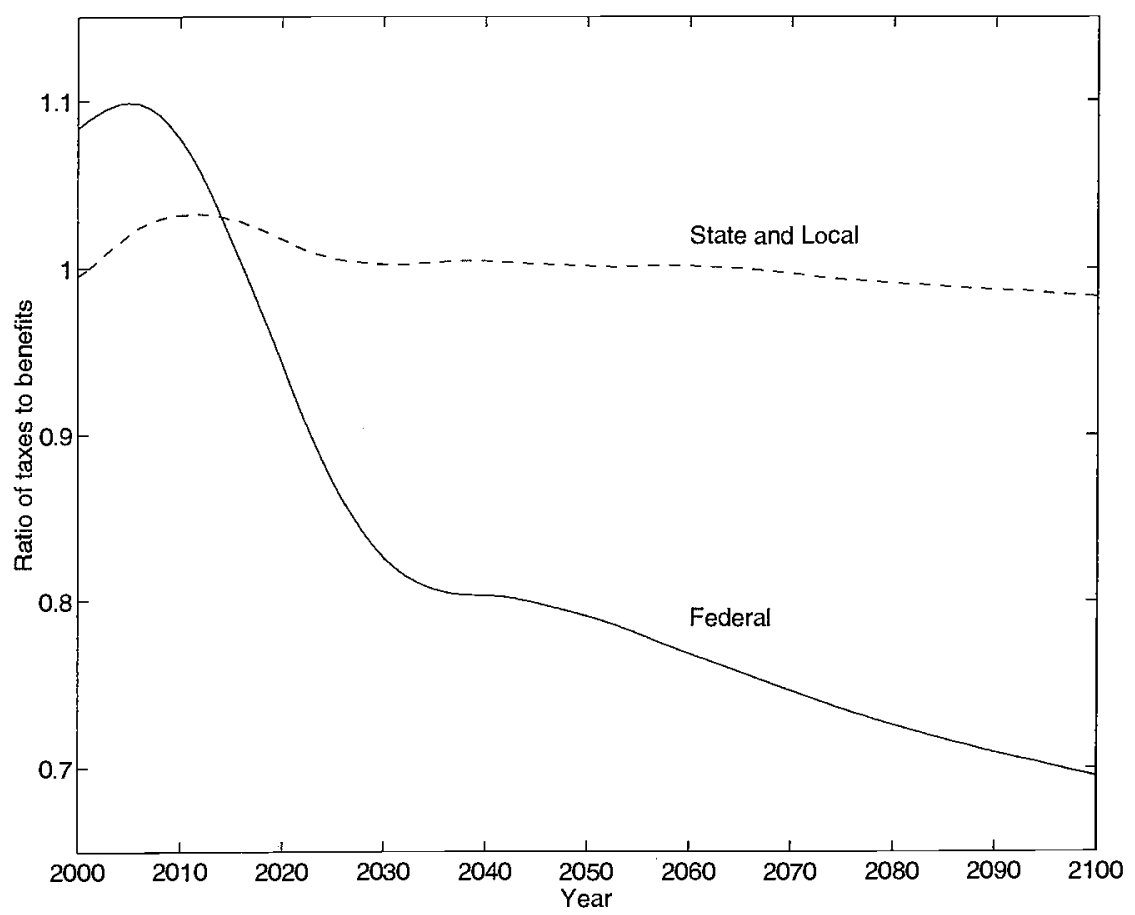

Note: The fiscal support ratio is calculated as the ratio of tax revenues to government expenditures, based on the age-specific tax and expenditure profiles for 2000 , applied to the projected age distribution for each period.

evaluated for the changing population age distributions in the future, using the current age profiles of taxes and benefits, $\beta(x)$ and $\tau(x)$. A similar calculation could be made using the projected profiles of taxes and benefits for some later year, and that would give somewhat different results.

Figure 4 plots the changing ratio of taxes to benefits over the next century, based on the central population forecast. It can be seen that there is hardly any effect at the state and local level; the ratio is quite constant over the century. At the federal level, however, population aging leads to a far bigger increase in benefit costs than in tax revenues. The same level of taxes represented by $\tau(x)$ would buy a level of benefits, $\beta(x)$, only 64 percent as high in 2075 as in 2000 . Put differently, we might say that population aging will raise the price of this benefit bundle $\beta(x)$ by 56 
percent $(0.64=1 / 1.56)$ over this century, in terms of after-tax income. ${ }^{5}$ As population aging alters this price, we might expect voters and policy makers to choose a lower level of the benefit age profile $\beta(x)$, and correspondingly more after-tax income for taxpayers. ${ }^{6}$ The net effect on aggregate benefit expenditures would be ambiguous. Although there will be a greater number of elderly people, each of them would receive lower benefits, and consequently the net effect of population aging on both aggregate benefit expenditures and on aggregate taxes and tax rates would be ambiguous. This interpretation, although ignoring the costs of transitions between program regimes, is broadly consistent with Gruber and Wise's (2001) results described above.

Note also that Figure 4 is based on the current program structure, and so it does not reflect the large expenditure increases per beneficiary that are projected for Medicare and Medicaid over the course of the twentyfirst century, due to projected increases in the quality and quantity of services consumed (Lee and Miller, 2001b).

Figure 4 showed a single forecast of the support ratio, as if we actually knew what the future would bring. Figure 5 presents probabilistic forecasts of the support ratio, showing the median value (which was plotted in Figure 4) along with 95-percent probability intervals. In early years, uncertainty results largely from uncertainty about fertility; the effects of uncertain mortality emerge only over the longer run. Variations in fertility have a strong effect on state and local finance once they affect the number of children of school age, that is, at age 5 or older. Thus the probability band for the state and local support ratio is very narrow for the first five years of the forecast, and opens up rapidly thereafter. The number of children has relatively little effect on the federal budget until they grow old enough to enter the work force and begin paying taxes, beginning around age 20 . Even then, the steep slope of $\tau(x)$ implies that uncertain fertility does not have a large effect on taxes for a number of years after that. Thus, the probability interval for the federal support ratio is very narrow for the first thirty years or so, and then widens as uncertainty about the size of the labor force grows. Uncertain mortality

5 Strictly speaking, this interpretation makes sense only when all difference in population age distributions is due to change in fertility, not mortality, and the system is unchanging over time. When mortality is declining, then the expected value of the benefit package over the life cycle will rise, since the expected duration of receiving benefits in old age increases. When the program system is changing over time, then the link between individual benefits over the life cycle and the current benefit package is not tight.

${ }^{6}$ In reality, the shape of $\beta(x)$ could also be changed, for example by favoring programs for children at the expense of programs for the elderly. Population aging also alters the cost of providing benefits to a child relative to the cost of providing benefits to an elderly person. 
FIGURE 5. Projected Fiscal Support Ratio by Level of Government, 2000 to 2100 (Median and 95\% Probability Interoal)

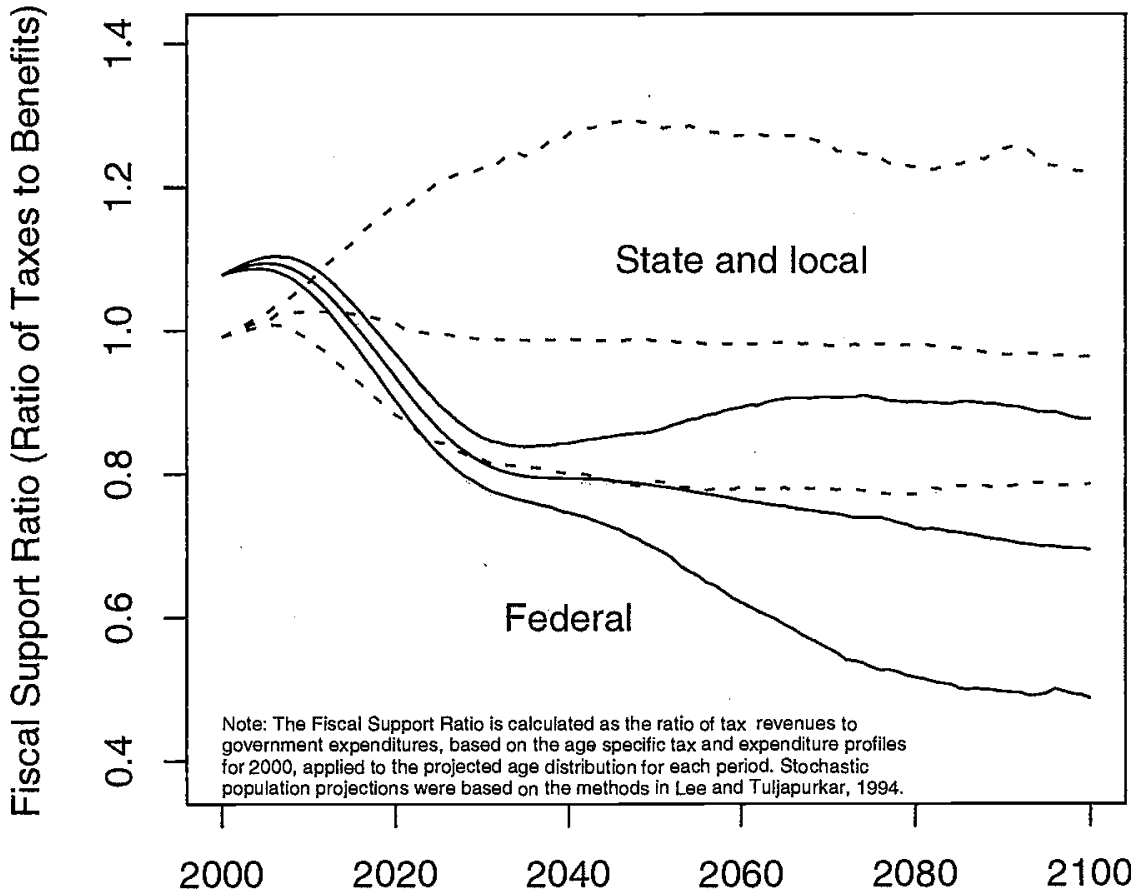

\section{Year}

Note: The fiscal support ratio is calculated as the ratio of tax revenues to government expenditures, based on the age-specific tax and expenditure profiles for 2000, applied to the projected age distribution for each period. Stochastic population projections were based on the methods in Lee and Tuljapurkar (1994).

contributes a small amount of uncertainty to the support ratio, but not much.

It is clear that demographic change is almost certain to cause serious pressures on the federal budget as the Baby Boom generations enter old age. Through 2040 or so, budgetary pressures can be projected with great confidence. After this it is not so clear whether pressures will continue to mount, or somewhat abate.

At the state and local level, the median support ratio shows no trend, but there is a great deal of uncertainty. It is not clear that there would be any advantage to planning for a growing school-age population, when that population is just as likely to decline, relative to taxpaying workers. 
In the long run, there is a negative correlation between errors in forecasting the state and local fiscal support ratio and the federal one. High fertility is costly for the state and local entities providing public education, but it allows lower taxes at the federal level, since it generates more workers to support the elderly. Thus, there is less uncertainty in the total fiscal support ratio than one would expect from looking at its constituent parts.

\section{CONSTRUCTING STOCHASTIC BUDGETARY FORECASTS}

We can build on these stochastic population forecasts to develop stochastic projections of government expenditures, assuming that the basic structure of programs is unchanged. To do so we need first to develop the linkage of population forecasts to costs of benefits, and second to incorporate some sources of economic uncertainty. ${ }^{7}$ Population is linked to benefit costs by the age schedule of costs of benefits currently received by a person in age group $x$. This average benefit profile is the $\beta(x)$ presented earlier in Figure 2. This schedule cannot be expected to remain fixed in the future, however, even under the assumption that program structure remains fixed. Benefits for most programs can be expected to rise as productivity increases. We will follow CBO in assuming that most benefits rise in real cost at the same rate as productivity growth, which raises per capita incomes and labor costs. Some programs, notably social security, Medicare, and Medicaid, require special treatment, however, as we now discuss.

For social security, we take into account the legislated change in the normal retirement age from 65 to 67 in the coming decades. Our projections of benefits are based on the actual rules governing benefits in relation to prior earnings (see Lee and Tuljapurkar, 1998a and 1998b, for details), and indirectly take into account such particulars as the notch generation, the selective effect of mortality at older ages, and the effects of loss of spouse on benefit levels.

Benefit costs for Medicare have typically been rising much more rapidly than productivity growth, and are expected to do so for the foreseeable future. We constrain our median projection for health care costs per enrollee at each age to follow the CBO (2000) assumptions (which are very similar to the 2001 HCFA/CMMS projection assumptions in Board of Trustees of the Federal Hospital Insurance Trust Fund, 2001) in which the rate

7 For a number of years, CBO published stochastic long-term forecasts based on these LeeTuljapurkar stochastic population forecasts, with deterministic economic variables. 
of increase per enrollee declines to an eventual level 1 percent per year more rapid than the growth rate of productivity. We differ, however, in taking into account the distribution of the population at each age by time until death. The Medicare costs of individuals have been shown to be closely associated with their proximity to death (Lubitz and Prihoba, 1984; Lubitz, Beebe, and Baker, 1995; Miller, 2001). In a projection, we know for each year what proportion of people at a given age will die within one year, one to two years, ten years, and so on, and can allocate health costs accordingly. Time until death thus serves as a kind of index of health status. We apply the rate of increase of per enrollee cost to each category of time until death separately (see Lee and Miller, 2001b, for details).

For Medicaid, we note that the proportion of the elderly population in long-term care facilities at each age has been declining for some time, presumably due to the improving health of the elderly population. We project this decline to continue, which partially offsets the increasing costs of care for those in institutions.

\section{DETERMINISTIC FORECASTS OF THE FISCAL EFFECTS OF AGING}

We will begin by considering some deterministic projections, then turn to stochastic ones.

Figure 6 plots projected government expenditures as shares of GDP for the federal government, and for state and local governments grouped together, as well as their sum. Excluded from these totals are interest payments on the federal debt, and benefits paid for pre-funded programs such as most state and local pensions and some insurance funds. Total expenditures are initially 25 percent of GDP, but are projected to rise above 40 percent of GDP by 2075 and to continue climbing thereafter. For the federal budget and overall, there is an acceleration in the rate of increase between 2010 and 2030 when the Baby Boom is reaching old age, but clearly that is only a part of the story, since the trend continues rapidly upward after 2040. At the state and local level, expenditures rise only mildly relative to GDP. Almost all the increase in the total is due to increases at the federal level, which is not surprising given the importance of federal transfers to the elderly. Federal expenses increase from 16 percent of GDP in 2000 to 30 percent in 2075, almost a doubling, and by 2100 they are approaching 40 percent.

It is also interesting to separate these expenditures by age group of the recipients. We define three categories: spending on the elderly, spending on children, and programs that are age-neutral. We have assigned 
FIGURE 6. Government Expenditures as Shares of GDP

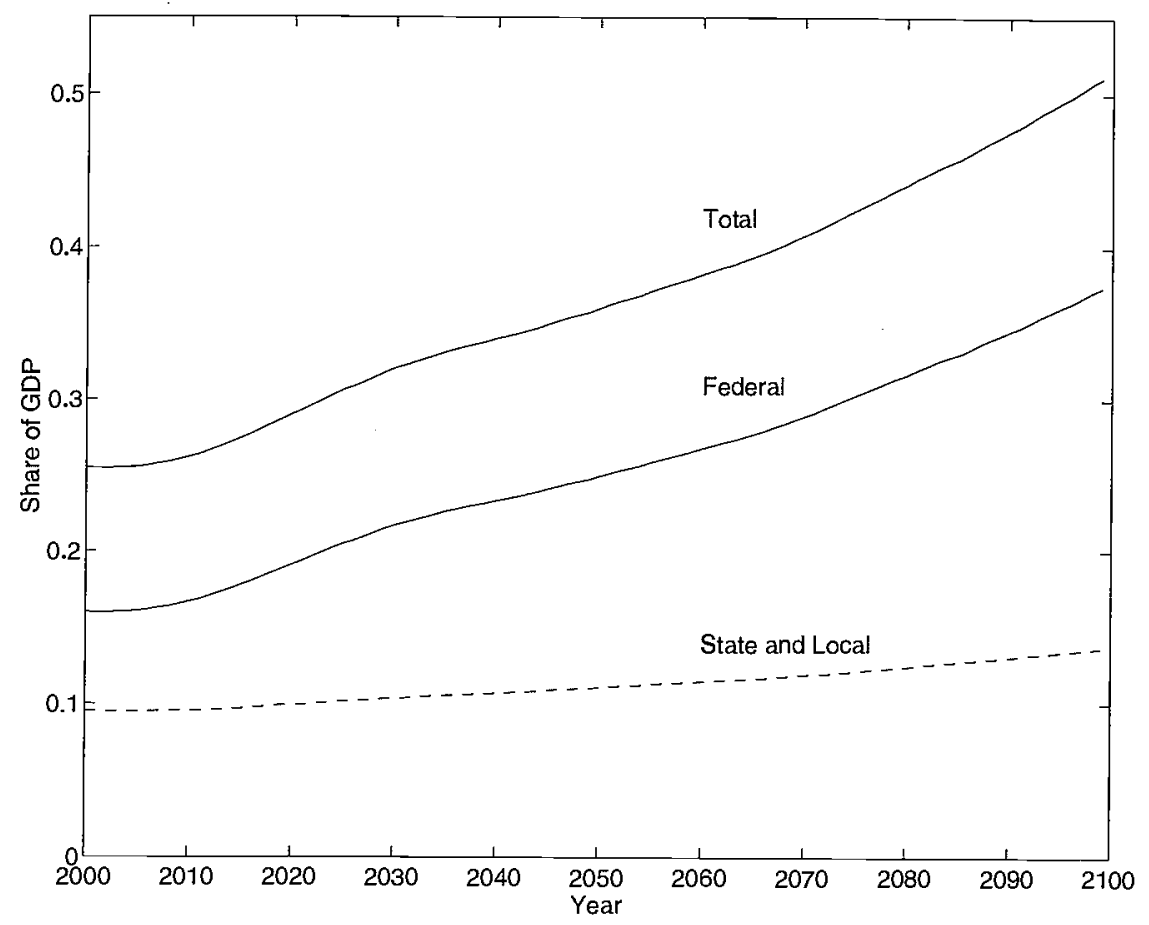

each program to one of these three categories, based either on the nature of the program or on some criterion such as the average dollar-weighted age of the recipient.

Figure 7 shows the result for all levels of government combined. Expenditures for children are flat over the next 100 years, relative to GDP. Age-neutral expenditures show some growth, but only to the extent that they include the non-institutional component of Medicaid, which grows faster than GDP due to excess growth in per capita health care costs. Almost all the projected increase in government spending over the next 75 years and beyond is due to increased expenditures on programs for the elderly. These rise from about 8 percent of GDP in 1999 to 21 percent of GDP in 2075, and they more than triple their share by 2100 .

It is also illuminating to look at the growth in expenditures by kind of program, rather than by age of recipient. Figure 8 shows the growth in projected expenditures for retirement programs (OASDI, federal employees, and railroad workers), health programs for the elderly (Medicare Parts A and B and institutional Medicaid), other expenditures for the 


\section{FIGURE 7. Government Expenditures per GDP by Age Group}

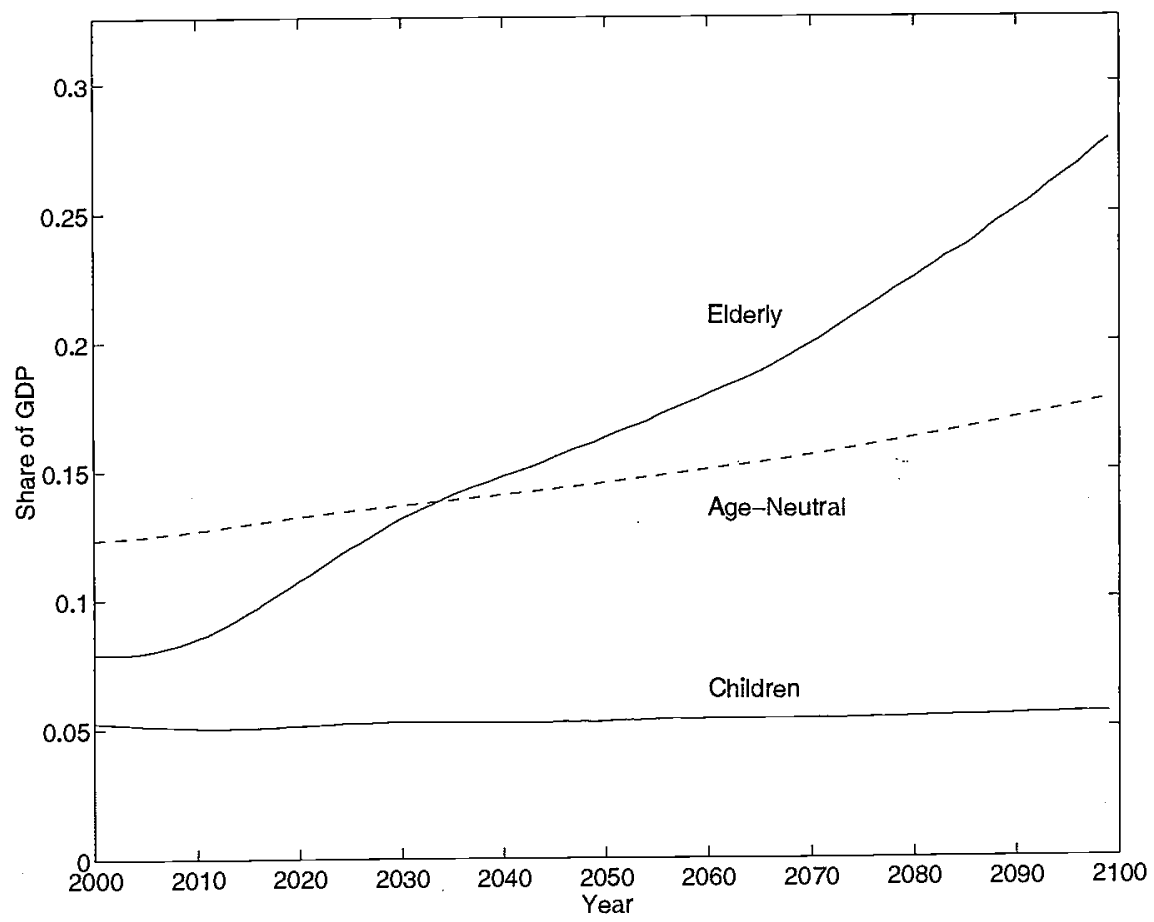

elderly, and all other federal expenditures. It is striking that the growth in expenditures for retirement programs, including social security, is such a small part of the projected growth in federal spending, contrary to the attention allocated to retirement programs in public discussions. Retirement accounts for only one-eighth of the total growth, with most of the rest due to growth in health care for the elderly. This very low share is in part due to the assumption of a 2.3-percent mean rate of productivity growth, which is 1.0 percent higher than the Social Security Actuaries' assumption, and which in itself would improve the summary actuarial balance measure from -1.89 percent of the present value of payroll to only -0.89 percent, making more than half of the projected imbalance disappear. Without this assumption, retirement programs would account for about a quarter of the projected expenditure increase. The projected increases in health care for the elderly are roughly half due to population aging (reflecting low fertility rather than mortality decline) and half to increases in costs per enrollee in excess of productivity growth (Lee and Miller, 2001b). The new assumptions by CBO and 


\section{FIGURE 8. Federal Expenditures per GDP by Type of Spending}

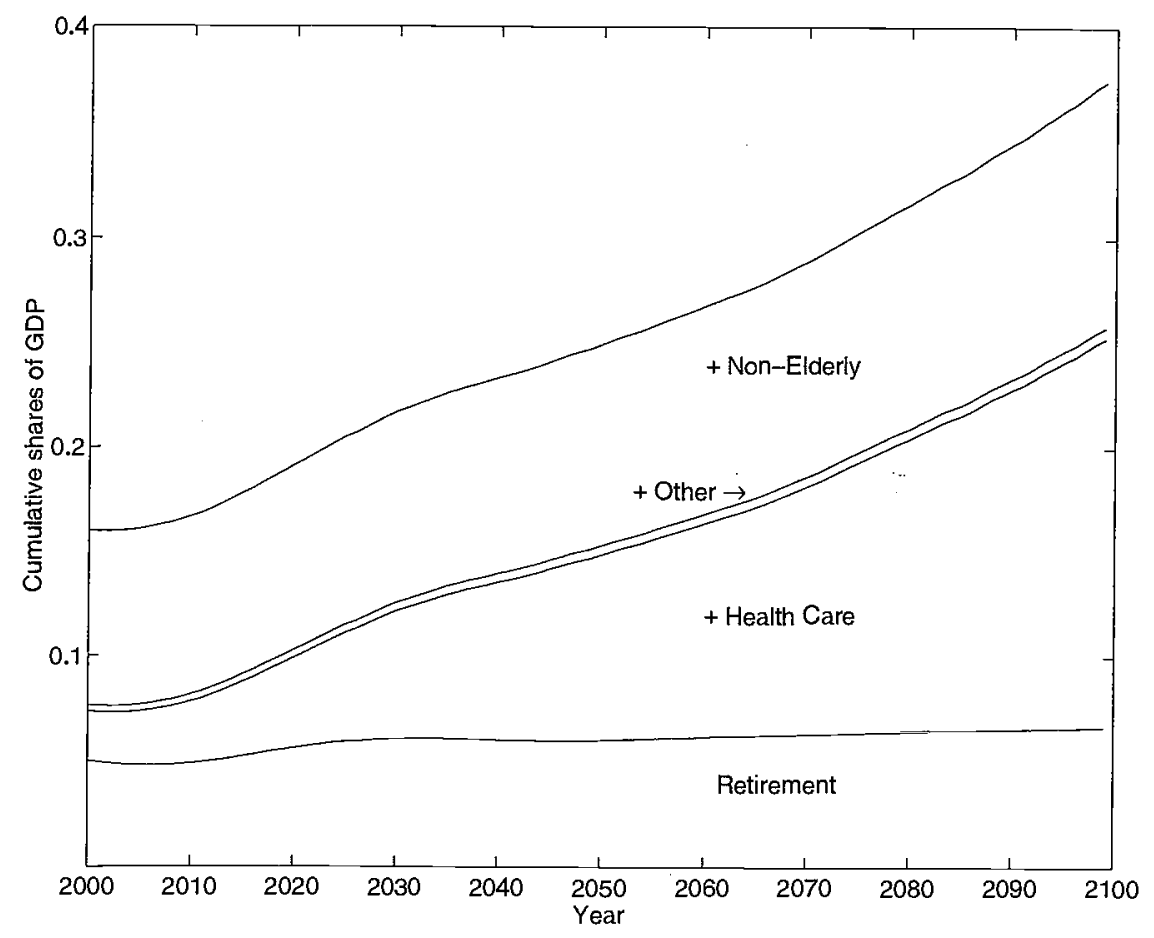

HCFA/CMMS on this excess rate of cost growth have a powerful influence on these projections.

\section{STOCHASTIC BUDGETARY PROJECTIONS}

So far we have not discussed how economic uncertainty is incorporated in our projections. We treat productivity growth and (where relevant) real interest rates and stock market returns as stochastic, following a modeling strategy similar to that used for fertility in the demographic projections (see the Appendix for details). That is, we model these as stochastic time series, and fit the models on historical data. The models we fit are constrained to have mean values that are consistent either with comparable official projections or the historical record, depending on the purpose of the forecast. Matching social security, our real interest rate averages 3 percent per year; we set labor productivity growth at 2.3 percent per year, roughly its postwar average; and real stock market 
returns are 7 percent per year, reflecting historical trends in the S\&P 500 . Thus for the most part, our fitted models are providing the structure of errors for our forecasts of economic inputs, but not their mean or median values, which are rather imposed. For the productivity growth rate, the standard error of the one-step forecast is 1.78 percent, so a 95-percent probability interval has a width of 7 percent, wide indeed. For the interest-rate model, the one-step forecast has a standard error of 2.04 percent, so the width of a 95-percent interval is over 8 percent. These intervals are very much wider than the high-low assumption ranges of Social Security, which have a width of 1 percent for productivity growth and 1.5 percent for real interest rates. However, it must be borne in mind that the stochastic interval refers to realized values in a single year, whereas the Actuaries' assumptions can best be thought of as referring to a long-run average.

The actual stochastic forecast is then carried out through stochastic simulation. A single stochastic trajectory is calculated by drawing random numbers to determine the forecast errors for the first year, which are then inserted in the appropriate equation for each input, along with the previous years' values, leading to a one-step forecast. Then the forecasts of population and benefit costs are derived mechanically from these forecasts of inputs. Then a second round of random numbers is drawn to generate the second year of the forecast, and so on. In this way one stochastic trajectory is forecast. We generate many such trajectories, generally at least a thousand, and then use the frequency distribution for outcomes of interest to estimate the probability distribution of the forecast. Outcomes include total expenditures on benefits, expenditures for a particular program, the date of Trust Fund exhaustion for social security, or the Trust Fund ratio, and so on. If desired, we can also project tax revenues in a similar way, and we can constrain tax rates to be adjusted so as to maintain some target such as a pre-specified debt-to-GDP ratio.

\section{STOCHASTIC PROJECTIONS FOR SOCIAL SECURITY}

We now turn to stochastic long-term projections of the finances of the social security system, drawing on Lee and Tuljapurkar (1998a, 1998b). We have already described the methods we have used, so we can move directly to results. Perhaps the most basic statistic is the cost rate, that is, the costs of benefits in a given year as a percentage of payroll in that year. In a pure pay-as-you-go system, with no accumulated trust fund, 
FIGURE 9. Cost Rate (Outgo as a Percentage of Taxable Payroll)

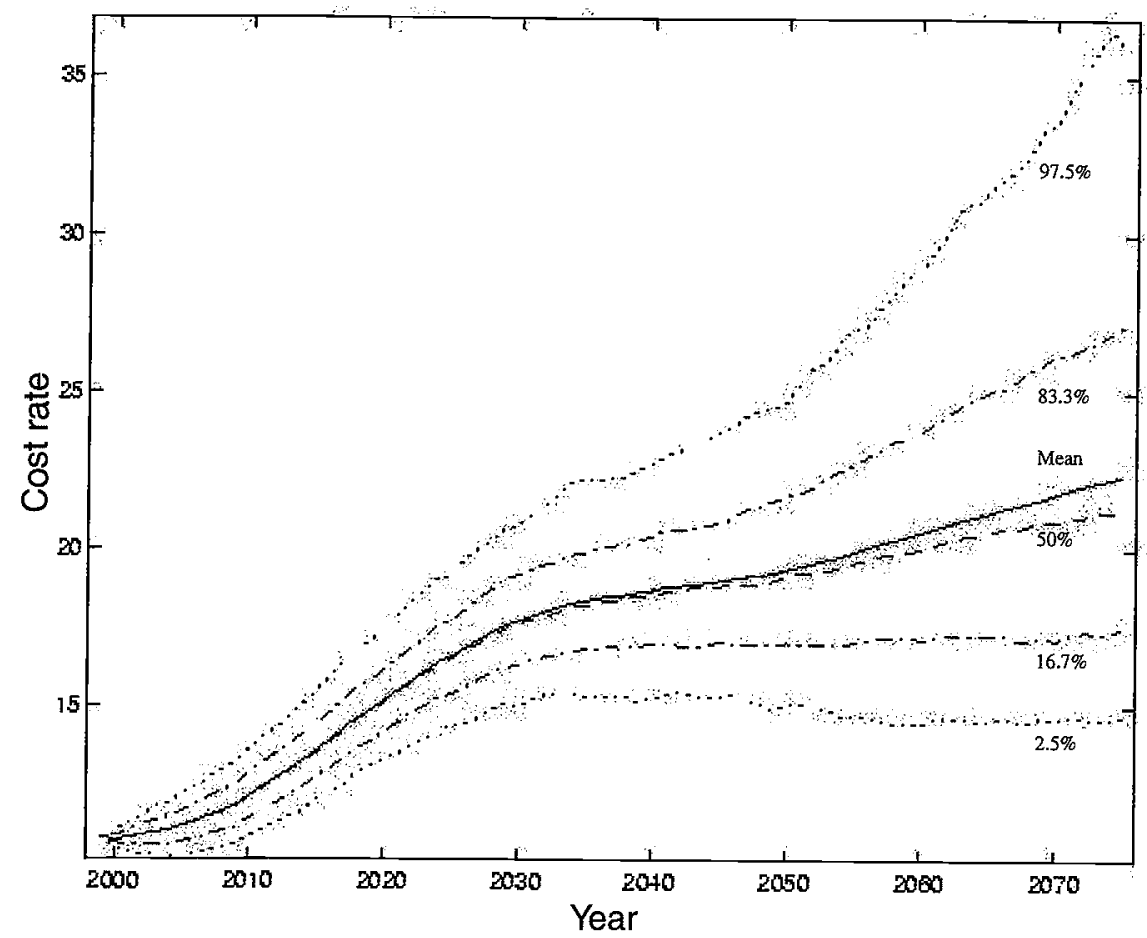

this would be the payroll tax rate for each year. Figure 9 plots various probability quantiles and the mean of the cost rate for each year through 2075 , with a projection base year of 2000 . These runs are based on the productivity growth-rate assumption of Social Security, so aside from our forecast of more rapid mortality improvement, our central forecasts should match closely those of the Social Security Actuaries for the same base year (Board of Trustees, 2000). The results reported here were generated by a stochastic simulation program written by Michael Anderson and Shripad Tuljapurkar, ${ }^{8}$ which can be accessed free via the Internet at http://simsoc.demog.berkeley.edu.

Users can modify many aspects of the policy environment, including plans for investing a portion of the Trust Fund in equities, raising the age at retirement, and raising the payroll tax rate.

${ }^{8}$ The results presented in Figures 9-12 are based on the output of this program, which is currently in beta testing and not guaranteed to be bug-free. 
We see that by 2075 , the median cost rate is 21.2 percent. There is a $2.5-$ percent probability that the cost rate will be only 14.6 percent, but also a 2.5-percent probability that it will be at least as high as 36.5 percent. These figures can be compared with the Social Security projections (Board of Trustees, 2000), which give 19.5 percent for the intermediate trajectory and 13.9 to 28.3 percent for the range. Our central forecast is about 2 percent higher, due to the more rapid decline in mortality that we project. Our lower 2.5-percent bound is similar to the SSA low cost scenario, but our high 2.5-percent bound is almost 7 percent higher-consistent with Figure 1, which showed much larger uncertainty in the upward direction for the OADR than indicated by either Social Security or Census. By construction (see the Appendix) the long-run means of our forecasts for fertility, for the productivity growth rate, and for the real interest rate are identical to those assumed by the Social Security Actuaries, while our projected life expectancy for 2075 is about three years higher.

We have compared our outcomes with those of the Actuaries, but it is important to note that ours are probabilistic whereas theirs are deterministic ranges and have no probabilistic meaning. It appears that the Actuaries' low cost scenario matches our lower 2.5-percent bound for the cost rate, while their high cost scenario corresponds roughly to our upper 86percent bound. That is, the chances that the cost rate will exceed the Actuaries' high cost boundary are more than five times greater than the chances of its failing to reach the low cost boundary.

There is relatively little uncertainty in the income rate, that is, tax income as a proportion of payroll, since the only uncertainty comes from revenues from taxes on benefits. However, the highly uncertain cost rate leads to large uncertainty in the various measures of net outcome. For example, our forecasts find a median date of fund exhaustion under current policy of 2038, very close to the intermediate projection of the Actuaries, 2037. We find a 2.5-percent chance of exhaustion by 2024 , versus 2027 for the high cost projection of the Actuaries. We also find roughly a 4-percent probability of exhaustion after 2075, compared to no exhaustion by 2075 for the Actuaries' low cost projection, which also has a healthy Trust Fund ratio at that point.

The Actuaries finds that an immediate rise in the payroll tax of 1.89 percentage points should restore actuarial balance over the 75-year horizon. We have also simulated the outcome assuming taxes are raised in this manner, from the current rate of 12.4 percent to 13.29 percent. Figure 10 depicts a histogram of the 1,000 probabilistic dates of exhaustion generated by our model under such a policy. Our method makes explicit what may be fairly intuitive: An immediate rise in payroll taxes designed to restore actuarial balance will only prevent Trust Fund bank- 
FIGURE 10. Histogram of 1,000 Dates of Exhaustion with Immediate Payroll Tax Increase of $1.89 \%$

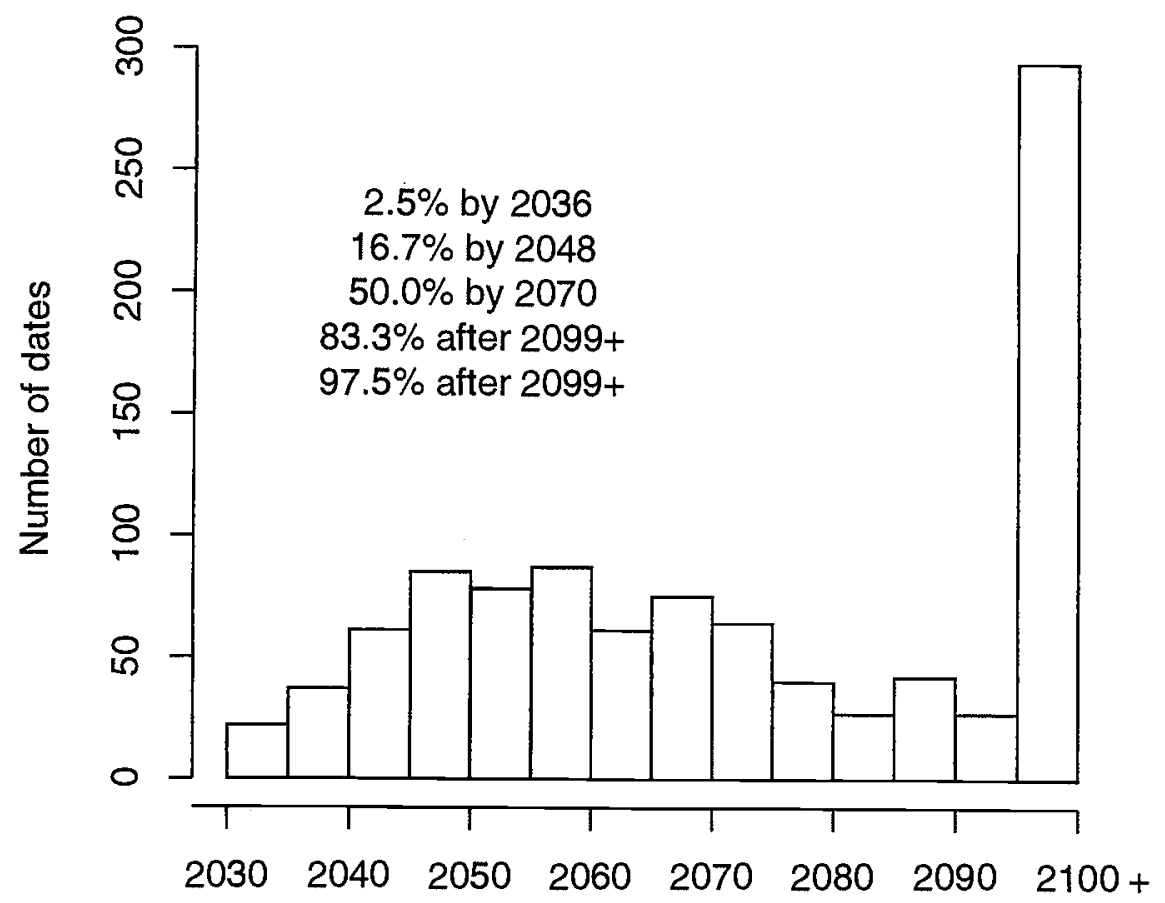

Year

ruptcy roughly 50 percent of the time. More strikingly, the lognormal dispersion of exhaustion dates in Figure 10 implies that the mode of the distribution actually occurs much earlier than 2075. Even a painfully large hike in the payroll tax today does not move the most frequently realized future date of bankruptcy past about 2055.

Figure 11 displays a histogram showing 1,000 realizations of the 75year actuarial balance dating from 2000, under the prescribed 1.89percentage-point rise in the payroll tax. The long left tail indicates that the chances of undershooting actuarial balance, denoted by 0 on the horizontal axis of the graph, are more widely dispersed than the chances of overshooting. That is, although the risks are roughly balanced under an immediate payroll tax hike, the downside risks are more costly.

Our stochastic framework lends itself particularly well to analyses involving social security's finances and risk. During the Clinton administration, 
FIGURE 11. Histogram of Actuarial Balances with Horizon to 2074

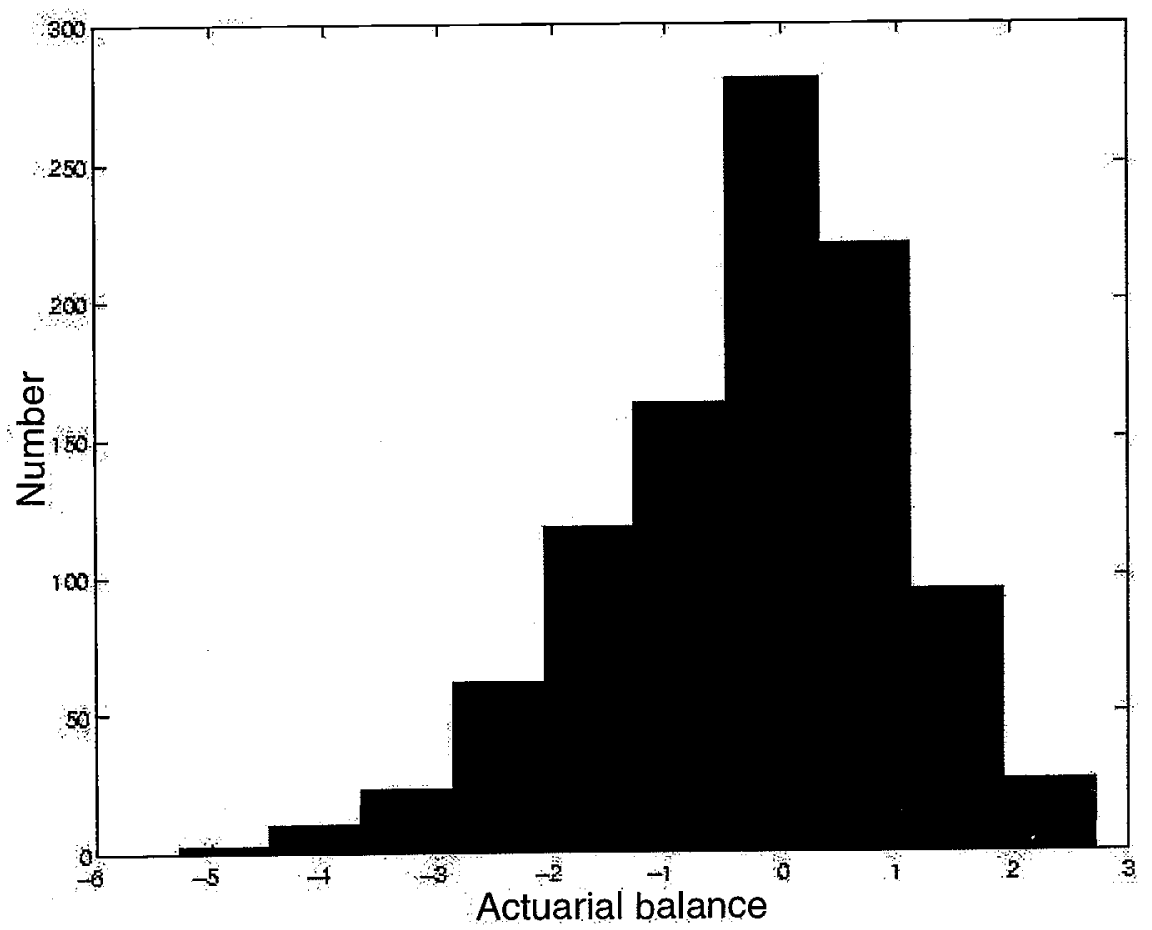

policymakers considered plans to invest part or all of the Trust Fund in equities, and currently the Bush administration is said to be weighing the option to replace part of the system with private accounts. An assessment of the riskiness of such plans is important in light of the uncertainty of stock market returns. Figure 12 presents a histogram of Trust Fund exhaustion dates under a particular investment plan: immediately placing 20 percent of the entire Fund balance in the S\&P 500 in 2000, and increasing that share to 50 percent by 2010 . The most striking characteristic of Figure 12 is that the distribution peaks soon around 2030-2035 and then tapers off very rapidly, even though the median date of Fund exhaustion is 2044. This dynamic is due to the risky nature of stock returns, which may potentially help social security's finances considerably, but at the same time will not change the expected date of bankruptcy very much. We have also simulated the effects of investing 75 percent of the Trust Fund in equities immediately. This leads to a mean fund balance equal to three times GDP in 2074. However, the median 
FIGURE 12. Histogram of 1,000 Dates of Exhaustion: Investing 20\% in 2000, Rising to $50 \%$ by 2010

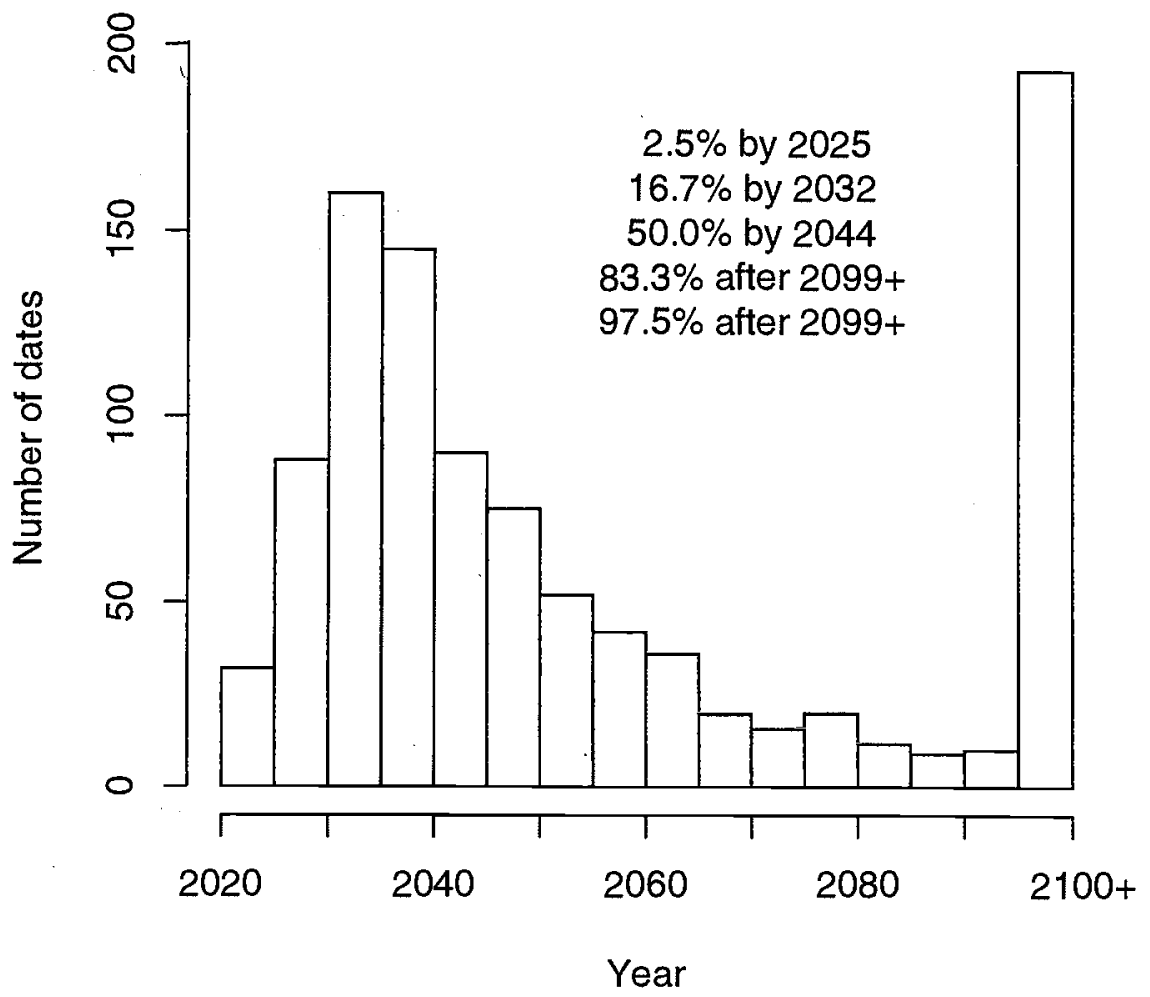

fund balance is minus half of GDP, and there is still a 63-percent chance of insolvency within 75 years. The mean outcome is a misleading measure because it is strongly affected by the long upward tail of the distribution of favorable stock market outcomes.

\section{STOCHASTIC PROJECTIONS OF MEDICARE COSTS}

Detailed projections of Medicare costs as a share of projected GDP are developed in Lee and Miller (2001b). We will not describe the methods or results in detail here, but rather will summarize some of the main points. Using the methods described earlier, the Lee-Miller median projection is that Medicare expenditures will rise from 2.2 percent of GDP now to 11 percent by 2075, quintupling. These dynamics are shown in 
FIGURE 13. Medicare as a Share of GDP: Median with 95-percent Probability Interval

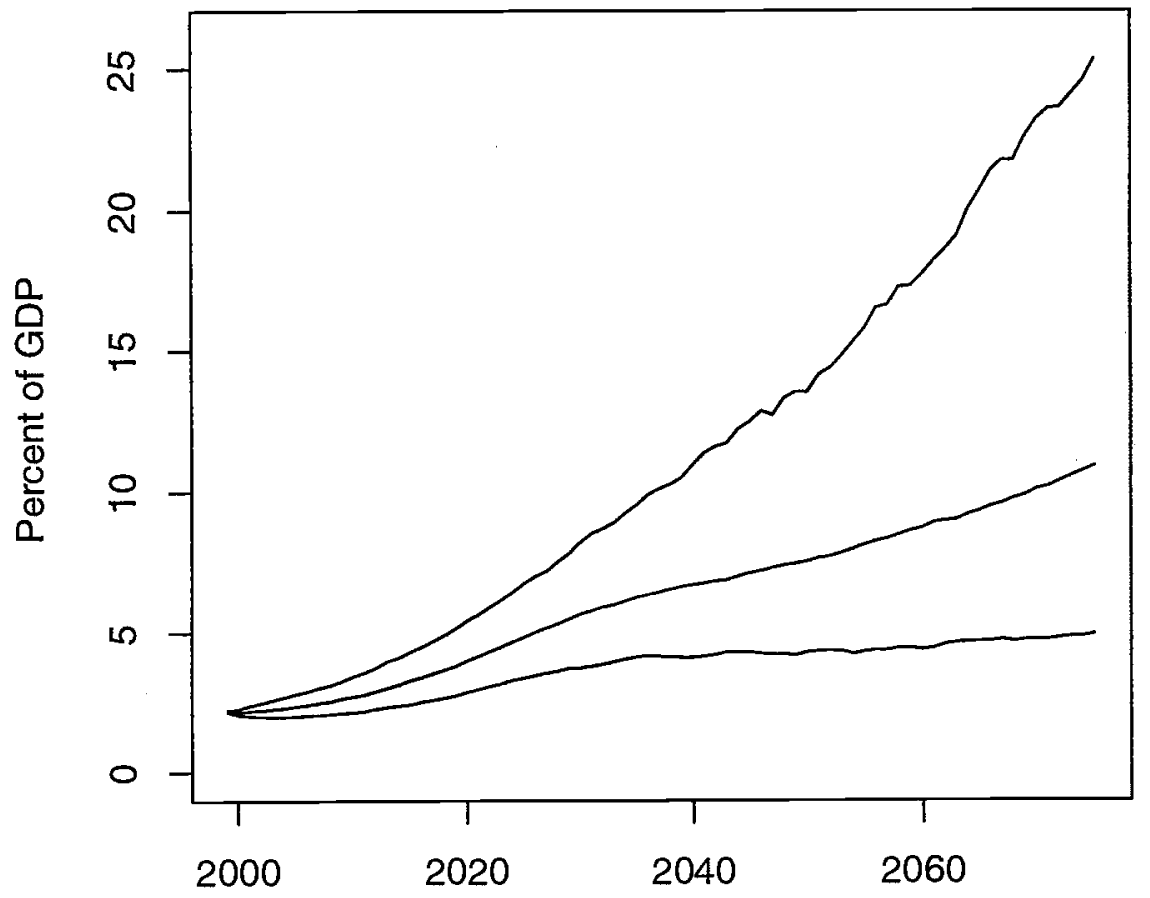

Year

Figure 13, where the middle line represents the median trajectory of Medicare's share of output. The Lee-Miller forecast stays close to the CBO forecast until it terminates in 2040. More rapid mortality declines projected by Lee and Miller have offsetting effects on projected health costs, since, as discussed above, lengthening life spans generally coincide with lengthening healthy life spans.

The projected increase in Medicare costs is huge, more than twice as big, as a share of GDP, as are total expenditures on social security today. Not surprisingly, however, the projected increase is highly uncertain. Before turning to the probability distribution for the forecast, however, we should consider the potential sources of error. First, there is demographic uncertainty. However, note that uncertainty arising through mortality is largely canceled by the parallel uncertainty in the health status of the population: If people live longer, it will be because they are 
in better health, or so the time-until-death approach assumes. Second, note that uncertainty about the rate of productivity increase is also filtered out, once we express the costs relative to GDP. If productivity growth is 1 percent per year more rapid than expected, then by assumption health costs will also grow 1 percent per year more rapidly than expected, as will GDP. The ratio of total costs to GDP is unaffected. Therefore the most important sources of uncertainty in the ratio of costs to GDP will be fertility and the size of the gap between the rates of increase in per-enrollee costs and productivity growth. We have fitted a time-series model to this gap over the past 50 years and then used it to assess the variance structure of the gap. ${ }^{9}$

With this background, we found that the 95-percent probability interval for the cost-to-GDP ratio in 2075 is 5 to 26 percent, as shown in Figure 13. That is, there is a 97.5-percent chance that the ratio will at least double, and a 2.5-percent chance that it will increase at least twelvefold. The uncertainty in the upward direction is more than twice as great as in the downward direction, similar to results we have seen before. This range of uncertainty reflects the U.S. experience with cost containment in the 1990s as well as earlier periods of more rapid growth. It is indeed difficult to plan for the future when there is so much uncertainty.

Comparing our 95-percent intervals with the CBO projections, we find that while in later years of their forecasts their high-low range is similar to our 95-percent range, for earlier years their range greatly understates the uncertainty. This is a common problem with the scenario approach for assessing uncertainty in projections.

\section{DISCUSSION}

Population aging is virtually certain to occur in the coming decades, and it will have a serious impact on the costliness of many government programs. We have assessed the fiscal pressures of population aging by examining its impact on many age-assignable government programs, as well as on tax receipts. However, recent economic change has underlined the dangers of ignoring the role of chance in formulating our plans. Many projections simply assume that the short-run or long-run future will unfold according to the pattern of the past few years, which is a risky practice. Good forecasts ought to provide some measure of this risk. Yet the scenario method, which is most widely used to incorporate

9 We have followed the suggestion of the Technical Advisory Panel for HCFA/CMMS in using a more general measure of health costs to calculate this gap, rather than specifically Medicare costs, and therefore we are able to go back in time before Medicare was launched in 1965. 
uncertainty in government forecasts, is seriously flawed. We, together with collaborators, have developed new and explicitly probabilistic methods for forecasting population and government expenditures, based on analysis of historical variability combined in many cases with expert judgement about central trends. Thus our analysis has had two goals: to examine the fiscal effects of population aging, and to do this in a probabilistic setting using stochastic simulation.

Beginning with the demography, we find that the OADR is virtually certain to increase by more than 50 percent in the 2030s. While it is possible that it will decline a bit thereafter as the Baby Boom generations die, more likely it will continue to increase after 2050, possibly by a great deal. The chance of very high ratios is substantially greater than indicated by Census or Social Security projections. Population aging raises the cost of the current structure of government programs (including those for children) relative to tax revenues, and makes a given package of life-cycle benefits more costly relative to the life-cycle tax payments necessary to fund it. We find that population aging is virtually certain to increase the costliness of current federal programs by 35 percent $( \pm 2$ percent) by the 2030 s, and with less certainty by 60 percent ( \pm 15 percent) in the second half of the century. Although population aging will not affect the costliness of average state and local programs in the mean or median forecast, there is considerable uncertainty about this $( \pm 20$ percent or so) after 2020. We expect that governments will respond to these aging-induced cost changes by altering program structures, as they have in the past.

Although it is unlikely that the current program structure will remain unchanged, it is nonetheless useful to project the consequences of maintaining it. Under this assumption (while the retirement age rises as currently legislated and health care costs per enrollee rise as projected), federal expenditures are projected to rise dramatically relative to GDP, from 16 percent of GDP in 2000 to 30 percent in 2075, almost a doubling, and by 2100 they are approaching 40 percent (these figures exclude interest payments on the debt and payments into pre-funded programs). State and local expenditures rise only modestly relative to GDP. Almost all of this increase is for programs going primarily to the elderly, which rise from 8 percent of GDP in 1999 to 21 percent of GDP in 2075 and which more than triple their share by 2100 . Programs for health care for the elderly account for the greatest part of this increase, with pensions a distant second.

Looking specifically at the social security system, although we believe the Actuaries underproject future mortality improvements, we are im- 
pressed by the quality of their projections. However, we find that they underestimate the risk of very costly outcomes. According to our probabilistic projections, the chances that the cost rate will exceed the Actuary's high cost boundary are more than five times greater than the chances of its failing to reach the low cost boundary. Raising the payroll tax rate by 1.89 percent, which according to the Trustees Report of 2000 would have put the system into 75-year actuarial balance, has relatively little effect on the probabilities of early exhaustion, raising the 2.5percent bound of exhaustion from 2024 to 2036, while raising the median date of exhaustion from 2036 to 2070; there would still be a 55-percent chance of insolvency within the 75-year horizon, with a median Trust Fund balance after 75 years of -6 percent of GDP. Investing some or all of the Trust Fund in equities may help solve the long-run problem in terms of average outcomes, but not in terms of more important measures such as the median outcome or the probability of insolvency.

Looking specifically at Medicare, which now costs 2.2 percent of GDP, we found a median share in 2075 of 11 percent, five times as great. The 95-percent probability interval for 2075 is 5 to 26 percent of GDP, so that there is a 97.5-percent chance that the ratio will at least double, and a 2.5-percent chance that it will increase at least twelvefold. The uncertainty in the upward direction is more than twice as great as in the downward direction, reflecting lognormality, as we have seen before.

Because probabilistic forecasts have only recently become available, research on their uses and implications has barely begun. The immediate impulse is to treat these forecasts as if they simply provided an improved high-low range. In fact, they contain much more information than that, and they can support more powerful uses and analyses.

One key question is how uncertainty should affect our planning. Should the possibility of worse outcomes lead us to take additional precautionary measures today, or should the possibility of better outcomes lead us to postpone action until we are sure action will be necessary? (See, for example, Auerbach and Hassett, 2001). Another important question is how different kinds of policies perform in the context of uncertainty. Do some reduce the uncertainty and others amplify it? For example, indexing retirement benefits to life expectancy at retirement (as has been done in Sweden) will reduce uncertainty for the pension system arising from future mortality, by passing on the consequences of the uncertainty from the taxpayers to the beneficiaries. Medicare costs turn out to be only slightly affected by uncertainty in future mortality, because of offsetting effects of health improvement on numbers of enrollees and costs per enrollee. Using the stochastic simulations as a kind 
of experimental laboratory, various policies can be assessed in terms of criteria such as intergenerational equity, rapidity of changes in taxes, rates of return, and so on.

\section{APPENDIX: METHODS USED FOR STOCHASTIC PROJECTIONS}

\section{A.1 Demographic Projections}

A.1.1 Mortality Let $m(x, t)$ be a central death rate for age $[x, x+5)$ and time $[t, t+1)$. Suppose we have a matrix of $X$ age-specific death rates over $T$ years. The Lee-Carter method estimates the model:

$$
\ln m_{x, t}=a_{x}+b_{x} k_{t}+\varepsilon_{x, t}
$$

using a singular-value decomposition (SVD) or some other appropriate method. This yields estimates of $a, b$, and $k$. A second-stage procedure adjusts $k$ to match exactly the life expectancy at birth implied by the $m_{x, t}$ for each year $t$.

We now have a time series of $k$ over $T$ years (for most purposes, we have used data from 1950 to 1999; for some purposes, we start in 1900). This time series is modeled using standard Box-Jenkins methods. (Tests for covariance with the residuals from the fertility model described below showed no association, so they were modeled independently). In most applications, it is well fitted by a random walk with drift. The fitted model for $k$ can then be used to forecast $k$ over the desired horizon, together with a probability distribution for each forecast year:

$$
k_{t}=k_{t-1}-1.029+\eta_{t} \quad \text { s.e.e. }=1.366
$$

From the forecasts of $k$, using equation (A.1), probability distributions and mean or median values of $m_{x, t}$ and the implied life expectancies can be calculated, along with probability distributions. These probability distributions will typically reflect the innovation error $\eta$ in $k$, along with the uncertainty of the estimate of the drift in the $k$ process. They typically will not include the $\varepsilon_{x, t}$ terms, nor the uncertainty in the estimates of the $a_{x}$ and $b_{x}$, which do not add much to the uncertainty after the first decade or two. On all of this, see Lee and Carter (1992) and Lee and Miller (2001a).

A.1.2 Fertility A similar approach is followed, but the fertility rates themselves, rather than their logs, are modeled. The model for agespecific fertility $g$ is 


$$
g_{x, t}=c_{x}+d_{x} f_{t}+v_{x, t}
$$

which is again estimated using a SVD. Time-series models applied to the history of fertility in the U.S. do not provide a plausible model or forecast for fertility, for various reasons, so the mean of the forecast is constrained to equal a level specified ex ante, and in practice is taken to equal the ultimate level of fertility assumed by the Social Security Actuaries, currently 1.95 children per woman. The fitted time-series model then provides crucial information about the variability and autocovariance of fertility. See Lee (1993) for a discussion of all these issues, and exploration of some alternative modeling strategies. The fitted fertility timeseries model is

$$
f_{t+1}=0.96 f_{t}-0.0037+v_{t+1}+0.52 v_{t}
$$

where the standard deviation of $v$ is 0.11 .

A.1.3 Immigration Immigration was projected deterministically following the assumption of the Social Security Actuaries, since it was thought better to treat it as a policy instrument than to attempt to forecast future policy.

A.1.4 Population Forecasts Initial conditions for the forecast come from the base-period population age distribution, taken from social security data. A single stochastic sample path is generated by drawing random numbers for the errors in the fertility and mortality equations, and thereby generating a trajectory of age-specific fertility and mortality rates over the desired horizon, say 100 years. Sample paths containing a total fertility rate below 0 or greater than 4 are discarded. In remaining paths, any negative age-specific birth rates are set to 0 . These are combined with the deterministic immigration rates. Using well-known accounting identities, the population forecast by age group is then calculated for this single sample path. The procedure is then repeated many times, sometimes 1,000 times and sometimes 10,000 times. The frequency distributions of outcomes of interest then provide estimates of the probability distributions for these outcomes, and joint distributions can be provided in a similar way.

\section{A.2 Economic Projections}

A.2.1 Productivity A demographically adjusted productivity growth series was constructed. First, an average wage profile by age and sex was calculated from the 1997 March Current Population Survey (CPS). Data 
on the age-sex composition of the labor force were also taken from the CPS, from 1948 to the present. The effect of the changing age-sex composition of the labor force, based on these age-sex weights for wages, was then calculated for each year since 1948 and used to adjust the official measure of productivity growth in the private non-farm business sector to remove the effect of the changing demographic structure of the labor force. The adjustment made little difference in general.

Next, a constrained-mean time-series model was fitted to the adjusted productivity growth series. As with fertility, the time-series model provides information about the variance, autocovariance, and cross-covariance of the series, but not about the long-run mean, which is imposed. An autoregressive model of order one was found to fit the data best:

$$
g_{t}-\mu_{g}=\beta\left(g_{t-1}-\mu_{g}\right)+\varepsilon_{g, t}
$$

where $\beta$ is estimated at 0.1640 with a standard error of 0.1408 . The standard deviation of $\varepsilon_{g, t}$ is 0.0178 . (The model was run on data in whole units rather than percentage points.) For general budget forecasts, including social security and other individual programs, before estimating the AR(1) we constrain the long-run mean $\mu_{g}$ to the historical post-W.W. II (arithmetic) average labor productivity growth rate, 2.3 percent. This is nearly 1 percent per year higher than the SSA assumption on labor productivity growth, but a bit below recent Congressional Budget Office assumptions. For some runs in which we are looking solely at social security, and wish to contrast the stochastic forecasts with deterministic ones, we constrain productivity growth to match that assumed by the Social Security Actuaries. Note that the rate of growth of covered wages in the social security system, which is a central component of the Actuaries' projections, is less rapid than labor productivity growth, since the former is affected by changing hours of work and by the changing share of total compensation that takes the form of untaxed benefits. We assume the wedge is 0.3 percentage point.

A.2.2 Interest Rates The bonds held in the Social Security Trust Fund are a special Treasury issue with a rate of return equal to an average of rates on longer term Treasury bonds. We use this special issue rate, minus the rate of inflation as measured by the CPI-U, as our baseline real interest rate. All balances in government trust funds and government debt held by the public earn interest at either this rate or a moving average of it, the latter of which is intended to capture the effect of the broader array of maturities held outside the Social Security 
Trust Fund. To project the real interest rate, we fit a VAR of order three that recognizes the conjoined behavior of bond returns $\left(r_{t}\right)$ and real stock returns $\left(s_{t}\right)$ :

$$
r_{t}^{*}=\alpha_{1} r_{t-1}^{*}+\alpha_{2} r_{t-2}^{*}+\alpha_{3} r_{t-3}^{*}+\gamma_{1} s_{t-1}^{*}+\gamma_{2} s_{t-2}^{*}+\gamma_{3} s_{t-3}^{*}+\varepsilon_{r_{t}, t}
$$

where asterisks denote detrended variables. (The analogous equation for stock returns in the VAR is not shown.) Point estimates of the $\alpha^{\prime} \mathrm{s}$ and $\gamma^{\prime} \mathrm{s}$ are, in order, $1.1785,-0.8029,0.4826,0.0065,-0.0232$, and 0.0052 . The standard deviation of $\varepsilon_{r, t}$ is 0.0204 . As with fertility and productivity growth, we constrain the long-run means of both series. Real stock returns are assumed to average 7.0 percent, while the long-run real interest rate is assumed to be 3.0 percent, mirroring the SSA assumption.

A.2.3 Economic Projections We begin with a stochastic sample path for population. From a recent March CPS, we calculate age-specific average labor earnings over all people in an age group (sometimes also by sex). We adjust this age profile multiplicatively so that in conjunction with the initial population age distribution, it implies aggregate labor earnings equal to a control total from the National Income and Product Accounts (NIPAs). Then a stochastic sample path for adjusted productivity growth is generated. For each forecast year, this sample path is used to shift the age-earnings profile multiplicatively. Together with the population sample path, this results in an implied aggregate level of labor earnings for each forecast year. If needed, a GDP forecast is also generated by assuming that labor earnings are a constant share of GDP, as is implied by the behavior of an economy with Cobb-Douglas production that is in a steady state.

\section{A.3 Fiscal Impact Projections}

A.3.1 Age Profiles Cross-sectional age profiles of per capita benefit costs (per member of the population, not just recipients) are estimated for the base period, using March CPS data for some programs, using administrative data for some others such as social security and Medicare, and sometimes combining data from surveys and administrative records. All profiles are adjusted to yield totals consistent with aggregate control totals when multiplied by the base-period population age distribution.

A.3.2 Social Security Benefits For these, a cross-sectional profile is not appropriate, because each generation's benefits are pegged to a proportion of its earnings level just before it retires, and the real benefit level is not subject to economic uncertainty thereafter. However, a generation's 
benefits do vary on a per capita basis as it ages, due to selective mortality, to changing proportions of widow(er)s and married couples, and to the continuing labor supply of some members combined with greater deferred benefits. We estimate this age-specific benefit profile for the older ages, and peg its initial value based on the stochastic productivity level just prior to retirement for each generation.

A.3.3 Health Costs The basic strategy was described in the text. Per enrollee health costs for each closeness-to-death category are projected according to a time-series model fitted to the gap between the growth rate of health cost data and productivity growth, with the mean gap constrained in future years to match the CBO projection assumptions, which are also similar to the recently revised HCFA/CMMS assumptions. CBO and HCFA/CMMS assume that the gap will continue indefinitely, but that it will decline to about 1 percent in a few decades (Lee and Miller, 2001).

\section{A.4 Budget Projections}

A.4.1 General Strategy Following CBO, we assume that most benefit age schedules rise with productivity growth; social security and health programs are exceptions, as discussed above. Each sample path will have different benefit cost profiles, due to stochastic productivity growth. The age profiles are then multiplied by the stochastic population forecasts to generate stochastic program cost estimates. Tax payments can be calculated using tax payment age profiles for various kinds of taxes, estimated cross-sectionally from a recent March CPS, and adjusted to match the NIPA control totals, or inferred from payroll tax rules and earnings. Taxes on capital are assumed to grow with GDP, since rents are assumed to be a constant share of income in the steady state. Trust funds are projected along sample paths using accounting identities and the stochastic interest-rate projections. Likewise, debt can be projected using accounting identities and a moving average of the same real interest rate. In such runs, Trust Fund balances and debt levels will be among the outputs. In some other runs, tax rates are set endogenously to comply with stipulated assumptions about limits on debt-to-GDP ratios, or on the Social Security Trust Fund ratio to costs. It is also possible to adjust benefit levels in addition to, or instead of, tax rates, to meet such imposed budget balance constraints.

A.4.2 Age-Neutral Budget Components Some important parts of the budget are not age-targeted. These include public goods, mainly expenditures on defense and research. We follow $\mathrm{CBO}$ in projecting these as a 
constant share of GDP. They also include private goods or quasi-public goods, such as expenditures for roads, sewers, police, fire, and so on. These are also assumed to be a fixed proportion of GDP, and therefore grow stochastically with population and productivity growth. Finally, there is national debt. The balance of flows into and out of national debt is determined endogenously by the budget balance each year.

\section{REFERENCES}

Auerbach, A. J., and K. A. Hassett (2001). "Uncertainty and Design of Long-Run Fiscal Policy." In Demographic Change and Fiscal Policy, Alan J. Auerbach and Ronald D. Lee (eds.). Cambridge, U.K.: Cambridge University Press.

Board of Trustees, Federal Hospital Insurance Trust Fund (2001). 2001 Annual Report of the Board of Trustees of the Federal Hospital Insurance Trust Fund. Washington: U.S. Government Printing Office.

Board of Trustees, Federal Old-Age and Survivors Insurance and Disability Insurance Trust Funds (2000). 2000 Annual Report of the Board of Trustees of the Federal Old-Age and Survivors Insurance and Disability Insurance Trust Funds. Washington: U.S. Government Printing Office.

Board of Trustees, Federal Old-Age and Survivors Insurance and Disability Insurance Trust Funds (2001). 2001 Annual Report of the Board of Trustees of the Federal Old-Age and Survivors Insurance and Disability Insurance Trust Funds. Washington: U.S. Government Printing Office.

Congressional Budget Office (2000). "The Long-Term Budget Outlook" (October), www.cbo.gov.

Congressional Budget Office (2001). "The Budget and Economic Outlook: Fiscal Years 2002-2011" (January), www.cbo.gov.

Crimmins, E. M., Y. Saito, and D. Ingegneri (1997). "Trends in Disability-Free Life Expectancy in the United States, 1970-90." Population and Development Review 23(no. 3, September):555-572.

Cutler, D., M. McClellan, J. Newhouse, and D. Remler (1998). "Are Medical Prices Declining? Evidence from Heart Attack Treatments." Quarterly Journal of Economics 113(no. 4, November):991-1024.

Cutler, D., and L. Sheiner (2000). "Demographic and Medical Care Spending: Standard and Non-standard Effects." In Demography and Fiscal Policy, A. Auerbach and R. Lee (eds.). Cambridge, UK: Cambridge University Press.

Freedman, V. A., and L. G. Martin (1999). "The Role of Education in Explaining and Forecasting Trends in Functional Limitations among Older Americans." Demography 36(no. 4, November): 461-473.

Fries, J. F. (1980). "Aging, Natural Death, and the Compression of Morbidity." New England Journal of Medicine 303:130-135.

Fries, J. F. (1984). "The Compression of Morbidity: Miscellaneous Comments about a Theme." The Gerontologist 24:354-359.

Gruber, J., and D. A. Wise (1999). Social Security and Retirement around the World. NBER Conference Report. Chicago: University of Chicago Press.

Gruber, J., and D. A. Wise (2001). "An International Perspective on Policies for an Aging Society." NBER Working Paper no. 8103.

Kannisto, V., J. Lauritsen, A. R. Thatcher, and J. Vaupel (1994). "Reductions in 
Mortality at Advanced Ages: Several Decades of Evidence from 27 Countries." Population and Development Review 20(no. 4):793-810.

Lee, R. (1993). "Modeling and Forecasting the Time Series of US Fertility: Age Patterns, Range, and Ultimate Level." International Journal of Forecasting 9:187202.

Lee, R. (1999). "Probabilitistic Approaches to Population Forecasting." In Rethinking Population Projections, supplement to volume 24 of Population and Development Review, W. Lutz, J. Vaupel, and D. Ahlburg (eds.).

Lee, R. and L. Carter (1992). "Modeling and Forecasting U.S. Mortality." Journal of the American Statistical Association 87(419, September):659-671; "Rejoinder," 674-675.

Lee, R., and T. Miller (2001a). "Evaluating the Performance of Lee-Carter Mortality Forecasts." Demography, v. 38, n. 4 (Nov.) pp. 537-549.

Lee, R., and T. Miller (2001b). "An Approach to Forecasting Health Expenditures, with Application to the U.S. Medicare System," under review.

Lee, R., and S. Tuljapurkar (1994). "Stochastic Population Forecasts for the U.S.: Beyond High, Medium and Low." Journal of the American Statistical Association 89(no. 428, December):1175-1189.

Lee, R., and S. Tuljapurkar (1998a). "Stochastic Forecasts for Social Security." In Frontiers in the Economics of Aging, David Wise (ed.). (Chicago: University of Chicago Press).

Lee, R., and S. Tuljapurkar (1998b). "Uncertain Demographic Futures and Social Security Finances." American Economic Review (May):237-241.

Lee, R., and S. Tuljapurkar (2000). "Population Forecasting for Fiscal Planning: Issues and Innovations." In Demography and Fiscal Policy, A. Auerbach and R. Lee (eds.). Cambridge, UK: Cambridge University Press.

Lubitz, J., and R. Prihoba (1984). "The Use of Medicare Services in the Last Two Years of Life." Health Care Financing Review 5:117-131.

Lubitz, J., J. Beebe, and C. Baker (1995). "Longevity and Medicare Expenses." New England Journal of Medicine 332:999-1003.

Manton, K., L. Corder, and E. Stallard (1997). "Chronic Disability Trends in Elderly United States Populations: 1982-1994." Proceedings of the National Academy of Science 94(March):2593-2598.

Miller, T. (2001): "Increasing Longevity and Medicare Expenditures." Demography 38:215-226.

National Research Council (2000). Beyond Six Billion: Forecasting the World's Population. Panel on Population Projections, John Bongaarts and Rodolfo A. Bulatao (eds.). Washington: National Academy Press.

Olshansky, S. J., B. A. Carnes, and A. Desesquelles (2001). "Demography. Prospects for Human Longevity." Science 291(23 February, no. 5508):1491-1492.

Roseveare, D., W. Leibfritz, D. Fore, and E. Wurzel (1996). "Ageing Populations, Pension Systems and Government Budgets: Simulations for 20 OECD Countries." Economics Department Working Paper No. 168. Paris: Organization for Economic Co-operation and Development.

Smith, J. P., and B. Edmonston, eds. (1997). The New Americans: Economic, Demographic, and Fiscal Effects of Immigration. Washington: National Academy Press.

Tuljapurkar, S., N. Li, and C. Boe (2000). "A Universal Pattern of Mortality Decline in the G7 Countries." Nature 405(June 15):789-792. 